Original Research

\title{
Evaluation of nature-based solutions implementation scenarios, using urban surface modelling
}

\author{
Emmanuel Panagiotakis 1, Dionysia Kolokotsa 2,*, Nektarios Chrysoulakis 1
}

1. Foundation of Research and Technology Hellas (FORTH), Institute of Applied and Computational Mathematics, Remote Sensing Lab, 100 Nikolaou Plastira Str., Vassilika Vouton 70013, Heraklion, Crete, Greece; E-Mails: panagiotakisman@iacm.forth.gr (E.P.); zedd2@iacm.forth.gr (N.C.)

2. Energy Management in the Built Environment Research Lab, School of Environmental Engineering, Technical University of Crete Kounoupidiana, GR 73100 Chania, Crete, Greece

* Correspondence: Dionysia Kolokotsa; E-Mail: dkolokotsa@enveng.tuc.gr

Received: 13 Apr 2021

Accepted: 22 Jun 2021

Published: 23 Sep 2021

Copyright: () 2021 by the author(s). This is an Open Access article distributed under the terms of the Creative Commons License Attribution 4.0

International (CC BY 4.0), which permits unrestricted use, distribution, and reproduction in any medium or format, provided the original work is correctly credited.

\section{Publisher's Note: Pivot} Science Publication Corp. remains neutral with regard to jurisdictional claims in published maps and institutional affiliations.

\begin{abstract}
The present paper aims to study the impact of Nature Based Solutions (NBS) on the urban environment. The Surface Urban Energy and Water balance Scheme (SUEWS) is used to quantify the impact of NBS in the city of Heraklion, Crete, Greece, a densely built urban area. Local meteorological data and data from an Eddy Covariance flux tower installed in the city center are used for the model simulation and evaluation. Five different scenarios are tested by replacing the city's roofs and pavements with green infrastructure, i.e., trees and grass, and water bodies. The NBS impact evaluation is based on the changes of air temperature above $2 \mathrm{~m}$ from the ground, relative humidity and energy fluxes. A decrease of the air temperature is revealed with the highest reduction (2.3\%) occurring when the pavements are replaced with grass for all scenarios. The reduction of the air temperature is followed by a decrease in turbulent sensible heat flux. For almost all cases, an increase of the relative humidity is noticed, accompanied by a considerable increase of the turbulent latent heat flux. Therefore, NBS in cities change the energy balance significantly and modify the urban environment for the citizens' benefit.
\end{abstract}

Keywords: Nature Based Solutions (NBS); SUEWS model; urban climate; urban energy fluxes 


\section{Introduction}

Due to the increase of the population in cities [1,2], the deep understanding of the driving forces that influence the urban environment is of major importance. Urbanization impacts the environment in several ways [3], affecting the urban climate and making cities potentially vulnerable. Studies around extreme weather conditions connect the city structure and characteristics with these conditions. Specifically, a natural hazard appears to be exacerbated from the urban form that contains factors such as urban surface cover, urban fabric, and surface structure [4]. The type of surface cover in urban areas can increase the in-surface runoff and sensible heat flux and reduce the evaporation to the boundary layer of an urban area compared to a naturally vegetated area. The implications of the changes in urban surface cover impact human comfort, flooding, and pollutant dispersion mixing of the boundary layer. Even though such fluxes are not measured, they are very important for the local authorities' political management and decision-making on a spatial scale, whether at the neighborhood, block, or city level [5].

According to various studies [6-9], resilience and sustainability should be taken into account in cities 'management in order to address the emerging challenges as well as the effects of climate on a large scale. The anthropogenic activity in urban areas changes the water and energy use considerably. Surface cover alterations in the urban environment increase the sensible heat flux and surface runoff and reduce evaporation, compared to the natural environment [8]. This is mainly due to the materials used for the construction, lack of vegetation, and the emission of pollutants that affect the net wave radiation. The climate of an urban region is influenced directly by the release of the energy into the atmosphere. Therefore, the study of the energy fluxes of urban areas is essential. According to S. Rafael [7] there are three ways to approach and study the energy fluxes. Those are:

- exploit the turbulent flux measurements produced from the Eddy Covariance (EC) method;

- use a combined method with flux measurements and simulations;

- use models that are designed to simulate the energy balance in the urban environment to link surface energy balance with climate.

With the third method, the surface cover can be modified to study the energy fluxes and climate behaviors among different scenarios of surface cover patterns inside a city.

The energy balance and, consequently, the energy fluxes are affected by several atmospheric variables. All net wave radiation is influenced by the solar radiation. Turbulent sensible and latent heat fluxes are influenced by atmospheric humidity, air temperature and wind speed. Soil moisture affects the latent heat, defined by precipitation. In turn, 
energy fluxes also affect the atmospheric variables [10]. Modifying these variables, different scenarios of energy fluxes can be studied to improve sustainability in urban environments.

Sustainability is defined as transforming living waves for the optimal support of the environmental and social conditions to human security, well-being, and health [11]. An urban environment's sustainability can be achieved using different alternatives such as Nature Based Solutions (NBS), or cool and highly reflective materials $[12,13]$. There is a strong interest in solutions that are based on natural ecosystems and lead to renaturing cities [14]. Studies on ecosystem-based solutions seem to be useful for water management, air quality, public health, and well-being [15]. Moving from an ecosystem-based approach to NBS to adapt and limit climate change impacts could be the solution for improving human health and well-being [16].

NBS determines actions that are based on the copy, the inspiration, or the support from nature [17]. According to [18] NBS is the deployment of various features and processes inspired and supported by nature. This leads to the adoption of sustainability in urban, rural, and natural environments at multiple scales while dealing with social, economic, or environmental challenges providing several benefits that support sustainable development and resilience.

Similar studies have been performed with modeling tools to predict the climate in urban areas by increasing the greenery inside the urban area or using cool roofs materials and cool pavements $[19,20]$. Rafael et al. [7] use SUEWS for Porto's city to study the behavior of energy balance inside the city according to these two scenarios. Another study in Einthoven uses NBS to assess local changes in heat fluxes and urban compaction [21]. Also, SUEWS has been tested and evaluated in different cities like Porto $[8,22]$, Vancouver, and Los Angeles [5,23], London and Swidon [3], Helsinki and Montreal [24], Dublin $[25,26]$, Shanghai [27]. The work performed in the framework of the BRIDGE project focuses on the urban metabolism using different models for the estimation of the local scale energy, water, carbon and pollutant fluxes [6]. Similar scenarios are studied by $\mathrm{Li}$ et al. [12] to explore the urban heat island over the Baltimore-Washington metropolitan area using Princeton Urban Canopy Model. Both of them use Weather Research and Forecasting model to supply the forcing meteorological data. The results seem to be similar even though the methods differ. Besides, Manoli et al. [28] pinpoint that using low vegetation to reduce the temperature through evapotranspiration could work mainly in cities with dry climatic conditions but not in tropical cities with high precipitation $\left(P>1000 \mathrm{~mm} \mathrm{yr}^{-1}\right)$. In tropical cities would be more useful to increase shading and ventilation than using evaporative cooling. Also, the high 
albedo materials, although they reduce the surface temperatures of cities, have a heating penalty during winter period $[29,30]$.

Although significant research is performed to show NBS potential to tackle urban heat island phenomenon, most of the studies are focusing on microclimatic scale using either field studies and data or microscale modelling [31-33] or to access city scale using satellite data [34,35]. The aim of the present research is to couple field studies' data extracted from meteorological station and EC tower with modelling techniques to evaluate the impact of NBS in city scale. The city of Heraklion, Crete, Greece is used as the case study. SUEWS model is used to investigate the energy fluxes in the center of the city [5,36-39]. The city's surface cover is changed to evaluate the energy fluxes when NBS are integrated into the city context.

The paper is structured in four sections. Section 2 includes the methodology, the study area, the data, and a description of the SUEWS model and its evaluation in the study area. The various NBS scenarios for the city of Heraklion are analyzed and discussed in Section 3. Section 4 summarizes and presents the conclusions of the overall work.

\section{Materials and Methods}

The methodology followed in the present work is depicted in Figure 1. The city of Heraklion, Crete, Greece is selected as a case study as it ensures access to:

- Detailed meteorological data from a meteorological station installed in the center of the city.

- Access to EC tower and energy fluxes data.

The SUEWS model (Section 3) is utilized to simulate the various fluxes in the city of Heraklion. The developed model is evaluated versus real data extracted by the EC tower. Data set from July 2018 is used for the evaluation of the model under the specific urban conditions. To evaluate the model, meteorological and net wave radiation data are collected from the EC tower and the radiometer, respectively. The monitoring procedure and mechanisms are described in Section 2.2.

The evaluated model is then used to assess the incorporation of NBS in the urban area and improve the local environment. 

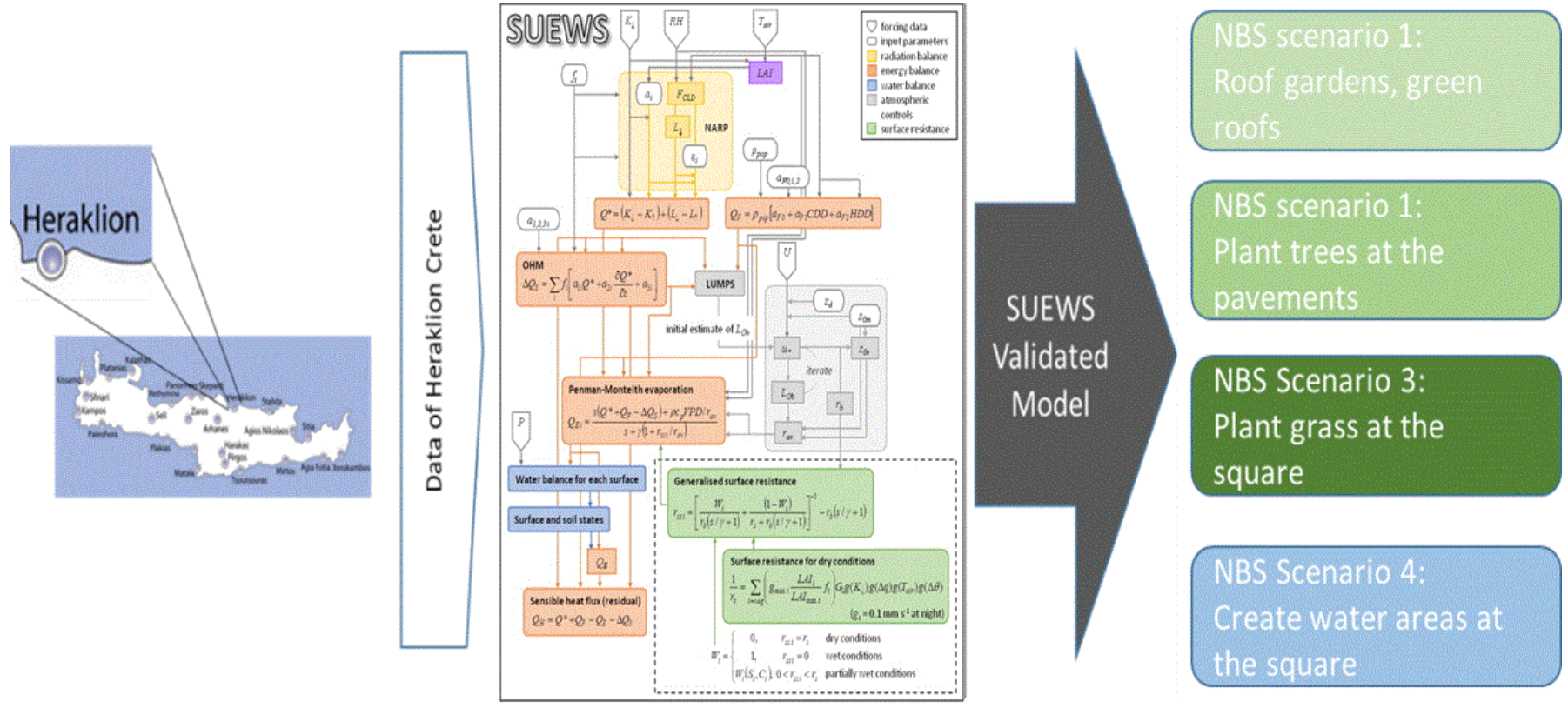

NBS Scenario 3:

Plant grass at the

square

NBS Scenario 4:

Create water areas at

the square

Figure 1 The methodology for the NBS evaluation in Heraklion, Crete, Greece (adapted from [3]).

\subsection{Description of the SUEWS model}

The SUEWS model is a simple simulation model of energy and water fluxes (Figure 2). The model simulates energy balance (Figure 3) [40],

$$
Q^{*}+Q_{F}=Q_{H}+Q_{E}+\Delta Q_{S}
$$

where $\mathrm{Q}^{*}$ is the net all-wave radiation, $\mathrm{QF}$ is the anthropogenic heat flux, QH is the turbulent sensible heat flux, QE is the turbulent latent heat flux and $\Delta \mathrm{Q} s$ is the net change in heat storage.

Water balance in urban areas is expressed by [41],

$$
P+I_{e}=E+R+\Delta S
$$

where $\mathrm{P}$ is precipitation, Ie is the water supplied by irrigation or street cleaning, $\mathrm{E}$ is the evaporation, $\mathrm{R}$ is the runoff (including above-ground runoff and deep soil runoff) and $\Delta S$ is the net change in the water storage (including water in the soil and water held on the surface).

The specialization of SUEWS is mainly for urban areas and examines seven types of surface. The first type is the paved surfaces areas, i.e., roads, pavements and car parks, the second type is buildings, the third is evergreen trees including shrubs, the fourth is deciduous trees including shrubs, the fifth is grass, the sixth is bare soil, and the seventh is open water like swimming pools, rivers, etc. 


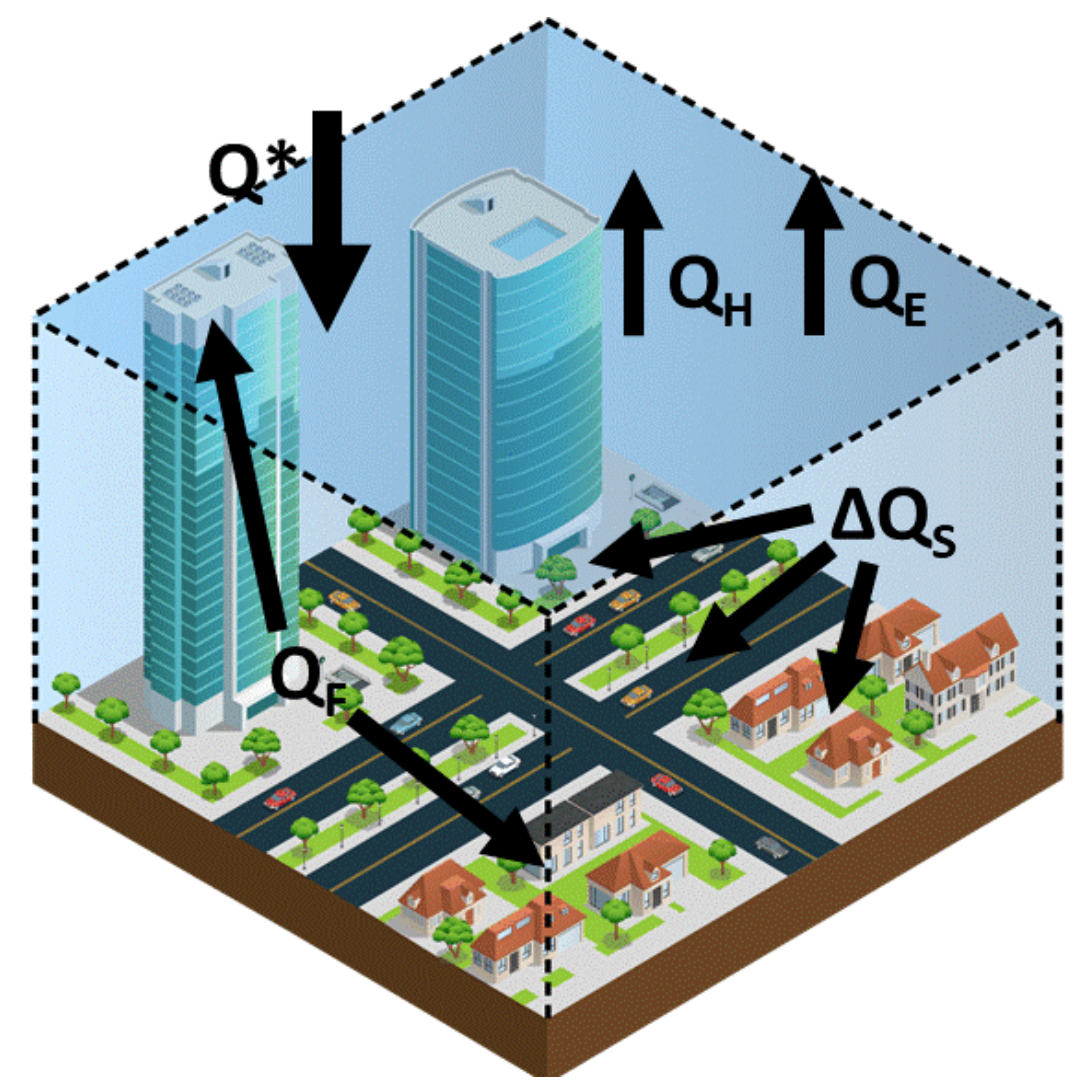

Figure 2 The energy fluxes of SUEWS model.

SUEWS development at first was focused on the urban water balance model [41] and the urban evaporation-interception scheme [42]. The SUEWS model is further developed with the addition of the following sub-models:

- The Objective Hysteresis Model (OHM) that calculates the $\Delta$ QS from [43].

- The Net All-wave Radiation Parameterization (NARP) [44] that provides the $\mathrm{Q}^{*}$.

- The Local-scale Urban Meteorological Parameterization Scheme (LUMPS) [45] that calculates an initial estimate of the atmosphere's stability.

The benefits of SUEWS are mainly two, i.e., the simplicity of the model and the undemanding requirements for inputs compared to other models. As a result, the execution for different years and multiple grids can be accomplished using typical computing facilities [3]. SUEWS can be characterized either as an urban-scale model for standalone use or as a tool for decision-making by customizing scenarios for the urban planners and policymakers that fit their needs [46].

SUEWS was initially developed, parameterized, and evaluated using data that were collected from Vancouver suburban areas $[5,41,42]$. Other evaluations have been performed using data from cities such as Los Angeles [5], Montreal and Helsinki [36,47] and Dublin [48]. 

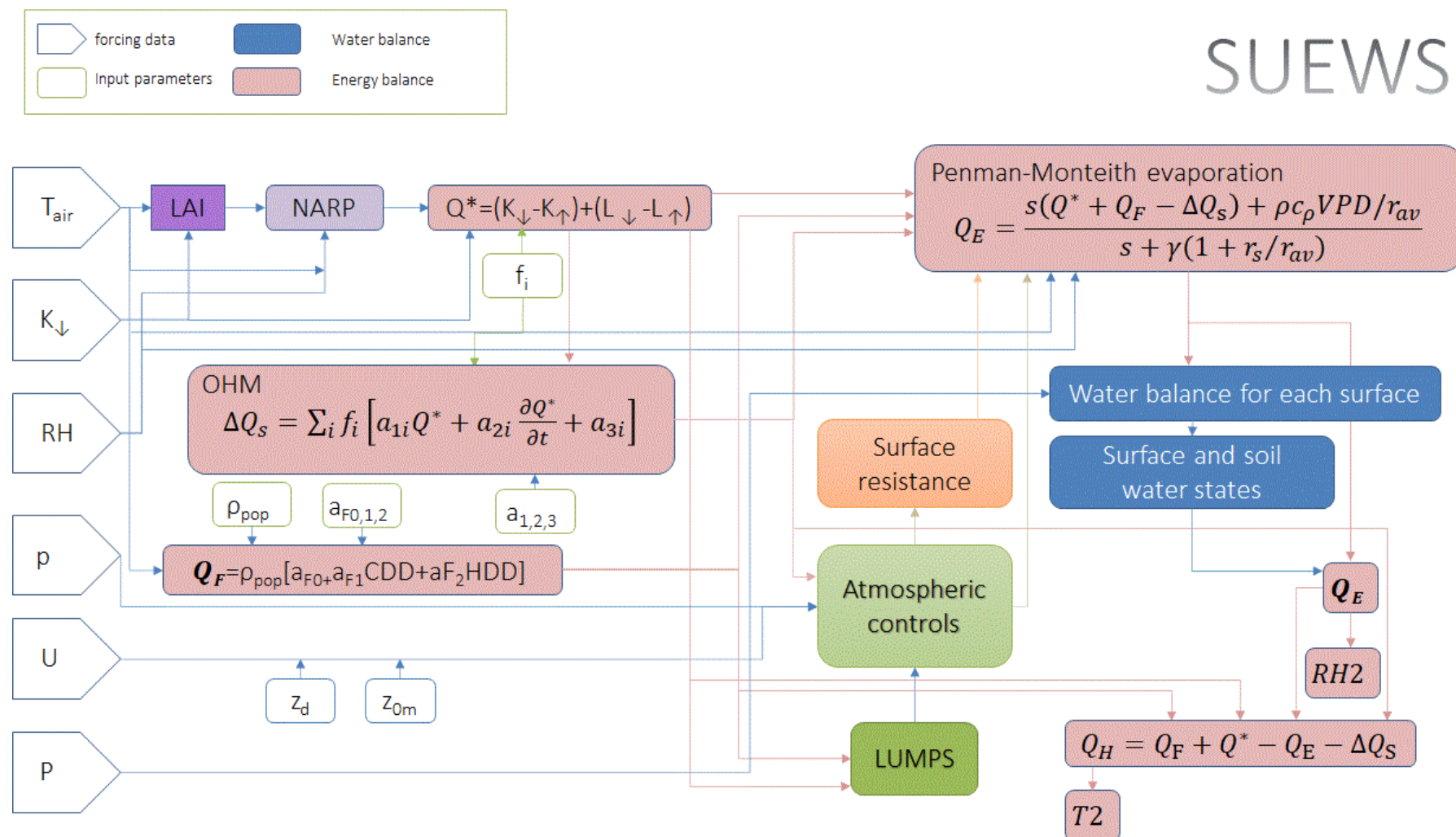

Figure 3 Overview of SUEWS model processes (adapted from Ward [3]).

\subsubsection{Net all-wave radiation model}

Net all-wave radiation is modeled using all radiations,

$$
\mathrm{Q}^{*}=(\mathrm{K} \downarrow-\mathrm{K} \uparrow)+(\mathrm{L} \downarrow-\mathrm{L} \uparrow)
$$

where $\mathrm{K} \downarrow$ is the short-wave incoming radiation, the $\mathrm{K} \uparrow$ is the outgoing short-wave radiation, $L \downarrow$ is the longwave incoming radiation and $L \uparrow$ is the longwave outgoing radiation. Short-wave incoming radiation is included to the input data while short-wave outgoing, longwave incoming and outgoing radiations are extracted using incoming shortwave radiation.

The calculation of outgoing short-wave radiation $(\mathrm{K} \uparrow)$ is performed using a bulk albedo (a). Bulk albedo is modeled using the albedo of the different types of surfaces with the area scheme's fractions. The values of the albedo used in SEUWS are selected from Oke [40] and modeled bulk albedo to 0.14, also used for London and Swindon [3] Vancouver and Los Angeles [5]. The albedo and emissivity values are tabulated in Table 1. The specific values are not appropriate for the Heraklion site due to the lack of observational data. The methodology proposed by Ward et al. [3] is adopted in the present case to perform adjustments that lower the SEUWS bulk albedo due to the presence of buildings and paved surfaces. Moreover, the specific methodology enables the bulk albedo changes due to seasonal and vegetation variations (e.g., deciduous trees). 
Table 1 The original values for albedo and emissivity have been used from Ward [3]. Different albedo values have been used for leaf-off/leafon (Min/Max) for deciduous trees.

\begin{tabular}{lll}
\hline Surface type & Original Albedo & Emissivity \\
\hline Paved & 0.12 & 0.95 \\
Buildings & 0.15 & 0.91 \\
Evergreen trees & 0.10 & 0.98 \\
Deciduous trees & $0.15-0.18$ & 0.98 \\
Grass & 0.21 & 0.93 \\
Bare soil & 0.21 & 0.94 \\
Water & 0.10 & 0.95 \\
Heraklion study site & 0.14 & - \\
\hline
\end{tabular}

The calculation of incoming longwave radiation $(L \downarrow)$ is performed taking into account the cloud cover. Cloud cover is estimated using Tair and $\mathrm{RH}[44,49]$. There is an overestimation for incoming longwave radiation that is due to the empirical relation that is used for the determination of cloud fraction [49]:

$$
\text { FCLD }(\mathrm{RH}, \text { Tair })=0.185[\exp \{(0.00019 \text { Tair+0.015) RH }\}-1
$$

The $L \downarrow$ is calculated using Eq. 5 [50],

$$
L \downarrow=[\varepsilon \text { clear }+(1-\varepsilon \text { clear }) \text { FCLD }] \sigma T 4 \text { air }
$$

where $\varepsilon$ clear is the clear-sky emissivity and $\sigma$ is the constant of StefanBoltzmann.

The calculation of outgoing longwave radiation $(L \uparrow)$ is performed using the effective radiative surface temperature T0 and a small part from $L \downarrow$,

$$
\mathrm{L} \uparrow=\varepsilon 0 \sigma \mathrm{T} 40+(1-\varepsilon 0) \mathrm{L} \downarrow
$$

Due to the inability of T0 determination in large areas [44] use an approximation replacing T0 with Tair,

$$
\mathrm{L} \uparrow=\varepsilon 0 \sigma \mathrm{T} 4 \mathrm{air}+0.08 \mathrm{~K} \downarrow(1-\alpha 0)+(1-\varepsilon 0) \mathrm{L} \downarrow
$$

where $\alpha 0$ is the bulk surface albedo.

\subsubsection{Anthropogenic heat flux}

Anthropogenic heat flux, QF, is the energy released as a result of human activities, including the energy released from buildings due to the use of electrical devices (for heating, cooling, etc.), transportation and the human metabolism [51,52]. QF has a significant impact on the energy demand in an urban environment [53-56]. The QF is estimated from SUEWS daily, according to Sailor and Vasireddy [57]:

$$
\mathrm{QF}=\rho \mathrm{pop}[\alpha \mathrm{F} 0+\alpha \mathrm{F} 1 \mathrm{CDD}+\alpha \mathrm{F} 3 \mathrm{HDD}]
$$

where $\rho p o p$ is the population density. The coefficients $\alpha \mathrm{F} 0,1,2$ can be specified separately for weekdays and weekends. Including the heating 
degree days (HDD) and cooling degree days (CDD) dependence in the formula QF is modeled with temperature variations reflecting the demand changes for building heating or cooling. The inventory data are used for the estimation of QF [58].

\subsubsection{Net Change in Heat Storage}

The calculation of the net change in heat storage, $\Delta \mathrm{QS}$, is realized with Objective Hysteresis Model (OHM) [43]:

$$
\Delta Q_{s}=\sum_{i} f_{i}\left[a_{1 i} Q^{*}+a_{2 i} \frac{\partial Q^{*}}{\partial t}+a_{3 i}\right]
$$

where $f$ is the surface cover fraction for each surface type, $i$, and $t$ is the time. The OHM coefficients a1,2,3 are different for each surface type and are selected from the literature. The coefficients are collected in different ways. Most of them are calculated from empirical fits to observational data [59-61] and the others form simulation studies [62-64].

According to the diurnal cycle shape, the OHM seems to perform well at suburban sites during the summer months, with a small underestimation during the daytime. In the winter, there is an underestimation of $\Delta \mathrm{QS}$, so the coefficients have to be adjusted for two seasons [3]. The inability of this study to evaluate $\Delta \mathrm{Q} s$ is due to the lack of observational data.

Considering the three-dimensional structure of the urban surface and including the wall area has been found that instead of improving performance using $\mathrm{OHM}$, there is a decrease when the walls are essential [65]. Even so, the expectation of building construction dependence seems to be reasonable. Arnfield and Grimmond [62] created a numerical model to nominate $\alpha 1,3$ coefficients' dependence with the increase of height-to-width ratio and materials density in buildings. The importance of considering the characteristics of buildings for the selection of appropriate coefficients values to set $\mathrm{OHM}$ is evident. Several values have been tested to connect with the environment and the urban structure $[47,59,66]$.

\subsubsection{Latent heat flux}

The aerodynamic and surface resistances are required to model the turbulent latent heat flux, QE, using the Penman-Monteith equation $[67,68]$ modified for urban areas [42]:

$$
Q_{E}=\frac{s\left(Q^{*}+Q_{F}-\Delta Q_{S}\right)+\rho c_{\rho} V P D / r_{a v}}{s+\gamma\left(1+r_{s} / r_{a v}\right)}
$$

where $\rho$ is the density of air, $c \rho$ the specific heat capacity of air at constant pressure, VPD the vapor pressure deficit, $s$ the slope of the saturation vapor pressure curve, $\gamma$ the psychometric constant, rav the aerodynamic resistance for water vapor and $r$ s the surface resistance. rav determines the rate at which water vapor is transported by 
turbulence between the surface and atmosphere. The surface resistance is analogous to the canopy resistance in natural environments and describes the environmental controls on evaporation for the whole urban surface $[5,43]$. Its reciprocal is the surface conductance gs. Despite several major land-surface models using $\mathrm{g} s$ to calculate evaporation and photosynthesis [69-71], it is challenging to simulate $\mathrm{g} \mathrm{s}$ in a generalized way. Various approaches have been suggested and in SUEWS a Jarvis-Stewart formulation $[5,72]$ is used:

$$
\sum_{i}\left(g_{\max i} \frac{L A I_{i}}{L A I_{\max i}} f_{i}\right) G_{1} g\left(K_{\downarrow}\right) g(\Delta q) g\left(T_{\text {air }}\right) g(\Delta \theta)
$$

where the sum is over the three vegetated surfaces and weighted by the surface cover fraction $f$ of each surface $I, g_{\max i}$ is the maximum conductance for surface $\mathrm{i}, L A I_{\max i}$ is the (maximum) leaf area index for each surface $i$ and $\mathrm{G} 1$ is a constant.

The functions $g\left(K_{\downarrow}\right), g(\Delta q), g\left(T_{\text {air }}\right), g(\Delta \theta)$ describe the control functions exerted by the incoming short-wave radiation $(\mathrm{K} \downarrow)$, specific humidity deficit $(\Delta q)$, air temperature (Tair) and soil moisture deficit $(\Delta \theta)$. In SUEWS_v2016a, the soil moisture deficit beneath vegetated surfaces is used, where soil moisture deficit is the loss of moisture from soil that hasn't be replaced from precipitation However, various empirical relations and alternative methodologies are provided in the literature for these control functions $[5,68,72]$.

Ward [3] presented a new functional dependence on the control functions [3] with the main objective of relaxing the control of soil moisture on evaporation. With the new set of parameters, the limiting $\Delta \theta$ is much larger and thus more suitable for the Heraklion site. The new relations are designed to be less restrictive so that unrealistic values of the surface conductance (and QE) are avoided. In suburban areas, the diurnal pattern of both observed and modeled $g$ functions exhibit the expected behavior during summer, mainly determined by the changing ratio of VPD/QE where VPD is the vapor pressure deficit. Conductances are much smaller and have a less clearly defined pattern in areas with less vegetation, reduced moisture availability, and lower evaporation rates. In winter, the diurnal cycle is shorter, more symmetrical, and smaller in amplitude at suburban areas, while observed night-time values are higher at urban and suburban sites, probably due to higher wind speeds and damp surfaces. Observed $g$ functions are also higher than suggested by the model during winter daytimes [3].

\subsubsection{Sensible Heat Flux}

The turbulent sensible Heat flux is calculated as the residual of energy balance:

$$
\mathrm{QH}=\mathrm{Q}^{*}+\mathrm{QF}-\Delta \mathrm{QS}-\mathrm{QE}
$$




\subsection{Description of the site and data requirements for SUEWS}

\subsubsection{The city of Heraklion}

The study focuses on the city of Heraklion $\left(35^{\circ} 20^{\prime} \mathrm{N}, 25^{\circ} 8^{\prime} \mathrm{E}\right)$. The city of Heraklion is the largest city on Crete and one of the larger in Greece. Heraklion has been selected in the past as a test urban area for the measurement of turbulent fluxes using a specific EC tower installed in the framework of URBANFLUXES project [73], which is part of the International Association for Urban Climate Urban Flux Network [74]. Heraklion is selected due to its cover/morphology, climate, and traffic/commuter. According to Koppen climate classification [75] Heraklion has a hot summer Mediterranean type Csa. The average temperatures in summer peaks can reach over $40 \mathrm{C}^{\circ}$ with a mean daily average of $25.7 \mathrm{C}^{\circ}$ for the July, the hottest month. In the summer days are warm to hot and dry (relative humidity drops from $68 \%$ in winter to $56.3 \%$ in the summer) with clear skies often with seasonal breezes. The types and properties of buildings are highly variable across the city. Residential neighborhoods and commercial areas are included inside the city center mix of low and mid-rise buildings. Most of the buildings in the city center's residential area are mainly old without any thermal insulation or building services such as heating ventilation and air conditioning. In the center of the city, buildings' density is quite high $(40-70 \%)$ while it is lower in the suburbs (10-30\%). The EC tower has been installed in the core of the Heraklion city center $\left(35^{\circ} 20^{\prime} 10^{\prime \prime} \mathrm{N}, 25^{\circ} 8^{\prime} 58^{\prime \prime} \mathrm{E}\right.$, elevation $30 \mathrm{~m}$ above sea level [76]. The position of the EC tower is marked with a yellow cross in Figure 4.

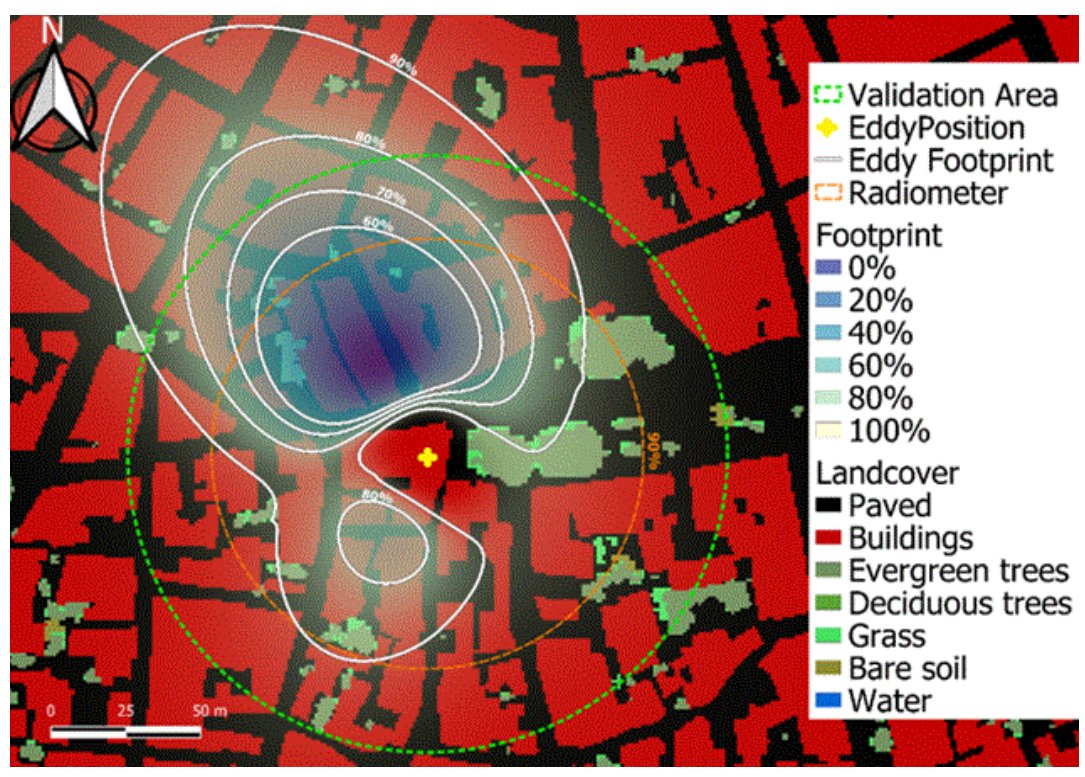

Figure 4 This image shows the site of the evaluation area. The EC tower and the simulated footprint that indicates the source area with the rate influence. The source area of the radiometer with the rate influence. 


\subsubsection{Monitoring data requirements}

The required data for the present study are:

- Meteorological and radiation data from the sensors installed in the EC tower (hourly averaged data). The meteorological station is a Campbell Scientific IRGASON and measures the following:

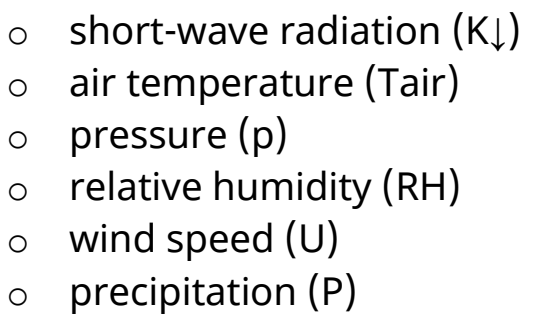

- Population density data from the national statistical services.

- Surface cover data. In this study Surface Cover data and Digital Surface Model (DSM) for buildings and trees are extracted from remote sensing $[73,77]$. Roughness length and displacement height are extracted from DSMs for trees and buildings using the Morphometric Calculator tool from UMEP processing tools. Morphometric Calculator tool is a plugin of UMEP environment that uses DSM to calculate morphometric parameters that are used the descriptions of the roughness of the surface and are included in various local and mesoscale climate models $[46,78]$. Due to the lack of initial soil moisture data, the value is set equal to $100 \%$ [79].

A Kipp \& Zonnen CNR1 Net Radiometer is installed to measure the fluxes used in the specific work.

The characteristics of the site are tabulated in Table 2.

Table $\mathbf{2}$ Characteristics of the source area for the Heraklion site.

\begin{tabular}{ll}
\hline & $\begin{array}{l}\text { Heraklion center urban } \\
\text { area data (Figure 4) }\end{array}$ \\
\hline Surface cover fractions & \\
- Paved & 0.404 \\
- Buildings & 0.532 \\
- Evergreen trees & 0.052 \\
- Deciduous trees & 0.000 \\
- Grass & 0.011 \\
- Ware soil & 0.001 \\
Population density [ha-1 $]$ & 0.000 \\
Mean building/tree height [m] & 57 \\
Roughness length [m] (z0) & $12 / 8.2$ \\
Displacement height [m] (zh) & 1.9 \\
Measurement height [m] & 14.2 \\
Location & 27 \\
\hline
\end{tabular}




\subsection{Model evaluation}

The model evaluation focuses on the local/neighborhood scale fluxes at $100 \mathrm{~m}$ radius around the EC tower's location. In Figure 4 the green dotted line defines the evaluation area. The EC observation source area depends on wind speed, direction, and stability [76]. The EC fluxes' origination area is calculated from the footprint model a few hundred meters of the flux tower. The upwelling source area of EC outlines are depicted in white color $(60 \%, 70 \%, 80 \%, 90 \%)$, and the radiometer isopleth is marked with the orange circle (Figure 4).

The SUEWS model used for the simulation is 3.15.4 UMEP and is running offline with $5 \mathrm{~min}$ time-step. The resolution of the various meteorological data that are required for the model is $60 \mathrm{~min}$. Linear interpolation is performed in a 5 min interval for all data apart from precipitation that is considered constant for a $60 \mathrm{~min}$. The model outputs are averaged to $60 \mathrm{~min}$ to be comparable with the obtained observational data [3]. The indicated evaluation area is selected to match the source area of the radiometer for $\mathrm{Q}^{*}$ [80] and urban fluxes (Figure 4). The model evaluation is performed using the data collected from the CNR1 radiometer and the EC tower collected from May to October 2018.

The variables used for the model evaluation are all radiation variables. Root Mean Square Error (RMSE) and determination (R2) are used to compare the modeled versus the measured variables.

The evaluation results for each variable are discussed in the following sub-sections.

\subsubsection{Net all wave radiation}

The measured vs modeled $K \downarrow, K \uparrow, L \downarrow, L \uparrow$ is depicted in Figure 5. The netall wave radiation evaluation results are depicted in Figure 6 . The $Q^{*}$ model approximation is very high, with $\mathrm{R} 2$ reaching 0.99 and a scatter that is really small (RMSE $=54 \mathrm{~W} \mathrm{~m}^{-2}$ ). The errors of $\mathrm{L} \downarrow$ and $\mathrm{K} \uparrow$ are those that mostly affect the differences of modeled versus measured $Q^{*}$. The underestimation of $\mathrm{K} \uparrow$ is due to the area structure of radiometers footprint so the radiometer also has an error from the real reflected short-wave radiation. The error of $L \downarrow$ is attributed to the estimation of the cloud cover; using the $L \downarrow$ observational data Q* may be improved. It is important that simulation results have the same behavior as observational data. The study aims to investigate the behavior of different scenarios in the surrounding area of urban and suburban environments (see Figure 1). 

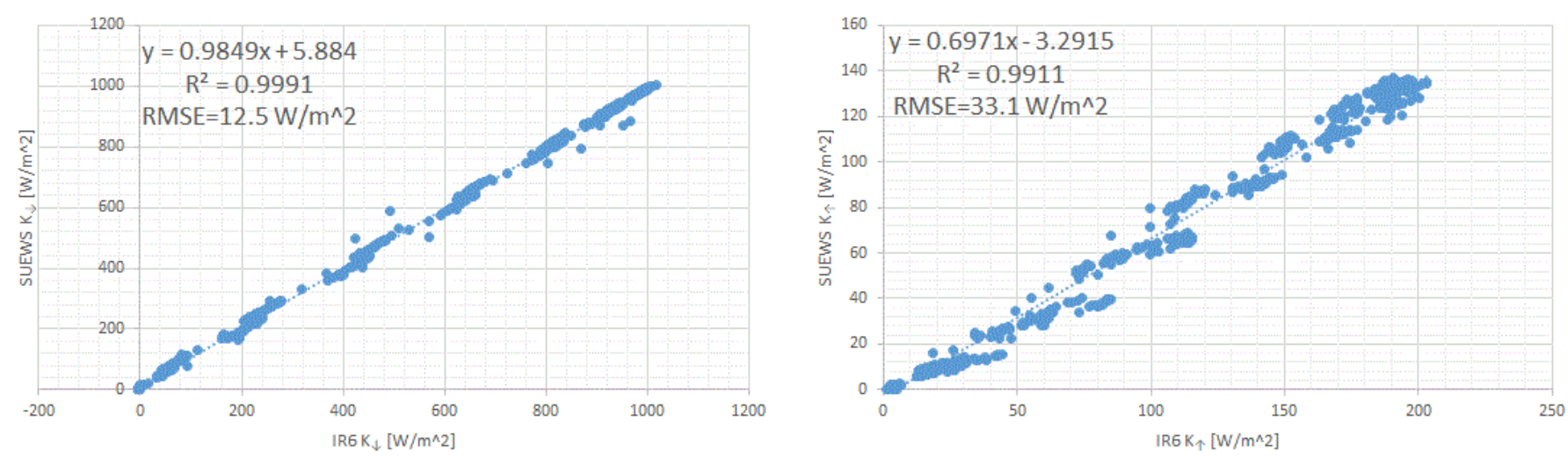

$L_{\downarrow}$
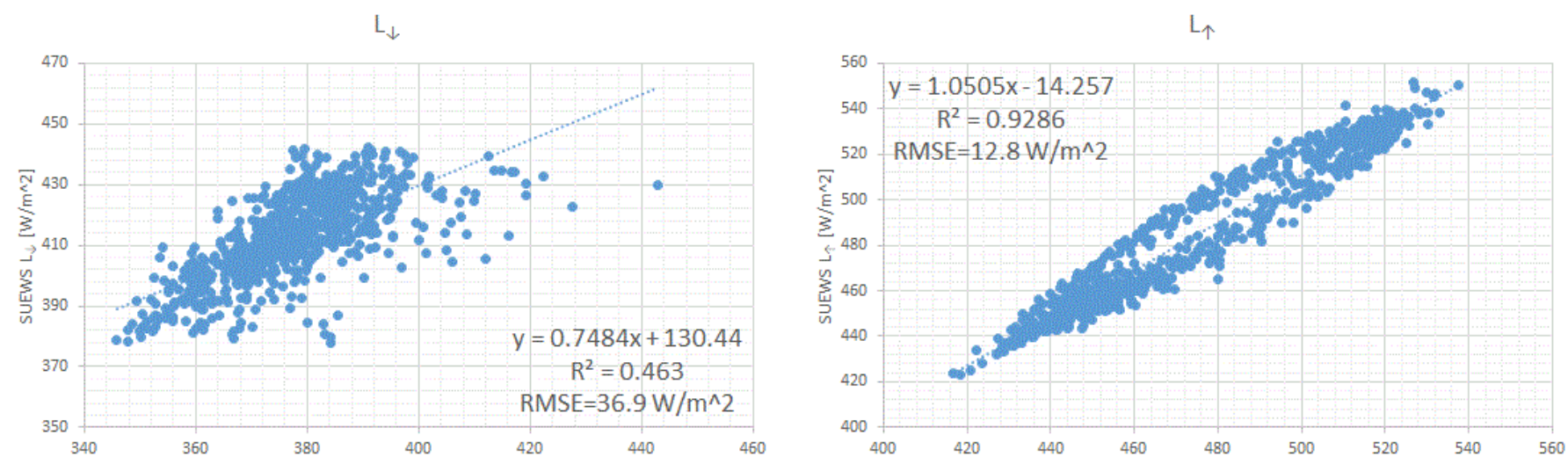

Figure 5 modeled radiations by SUEWS versus observed from IR6 sensor.

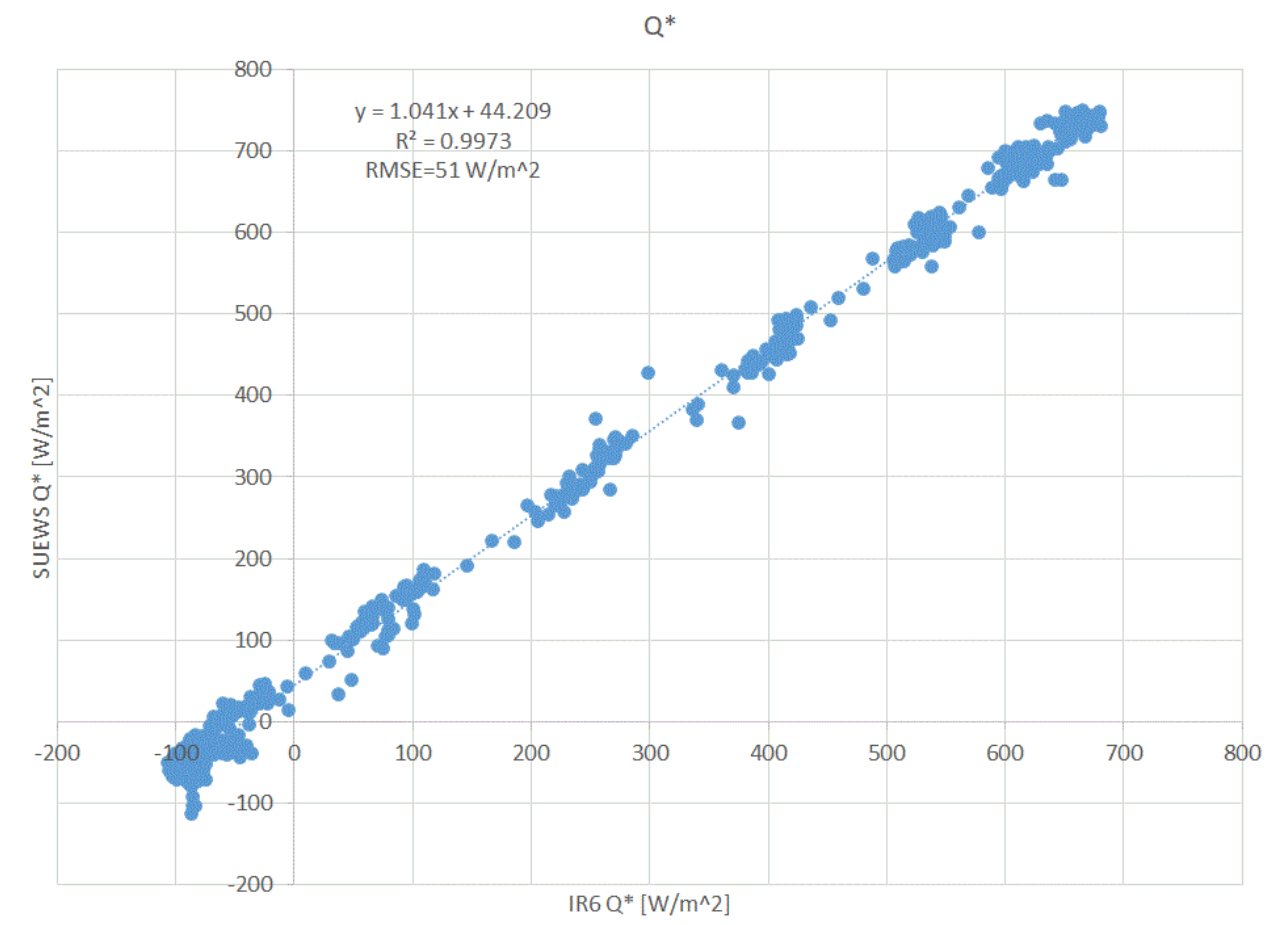

Figure 6 Modeled Q* from SUEWS versus IR6 calculated Q*. 
The $\mathrm{Q}^{*}$ overestimation (Figure 7 ) is attributed to the following factors:

- The existence of street canyons in the larger source area of the CNR1 radiometer affects the overall bulk albedo $(\approx 0.2)$ [81]. The model used for the calculation of the albedo does not include the morphology of the area. The lack of optical interaction between paved and CNR1 radiometer overestimates the observational albedo [3].

- The CNR1 radiometer is installed in a site to provide radiative fluxes that represent the EC footprint. On the other hand, the EC footprint is dynamic. It depends on the site's characteristics and meteorological conditions (wind, etc.) instead of the radiometer's source area that is much smaller and constant in time and space.

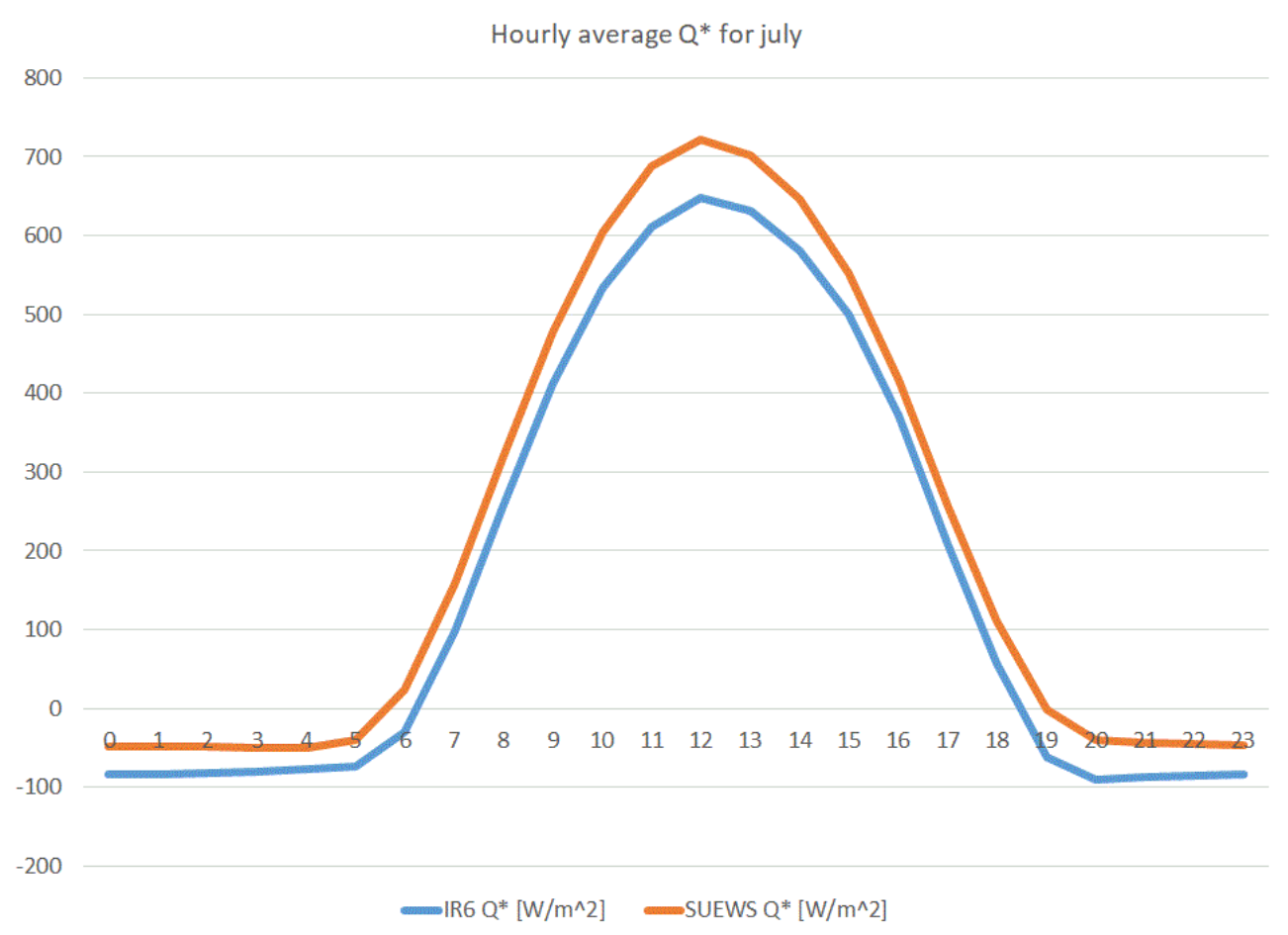

Figure 7 Hourly average $Q$ * for July. There is a small overestimation for every hour of the day but still has the same scheme as the albedo is not the same for the reason mentioned before.

\subsubsection{Sensible heat flux}

The monitored versus modeled turbulent sensible heat flux is depicted in Figure 8. Turbulent sensible heat flux is calculated as the residual of energy balance. Therefore, the error of each one heat flux is accumulated to turbulent sensible heat flux. The RMSE is $61.36 \mathrm{~W} \mathrm{~m}^{-1}$, which is reasonable due to error propagation and the EC's irregular source area that changes by time according to the wind speed, wind direction, atmospheric stability, and lateral dispersion qualities of the flow [76]. 

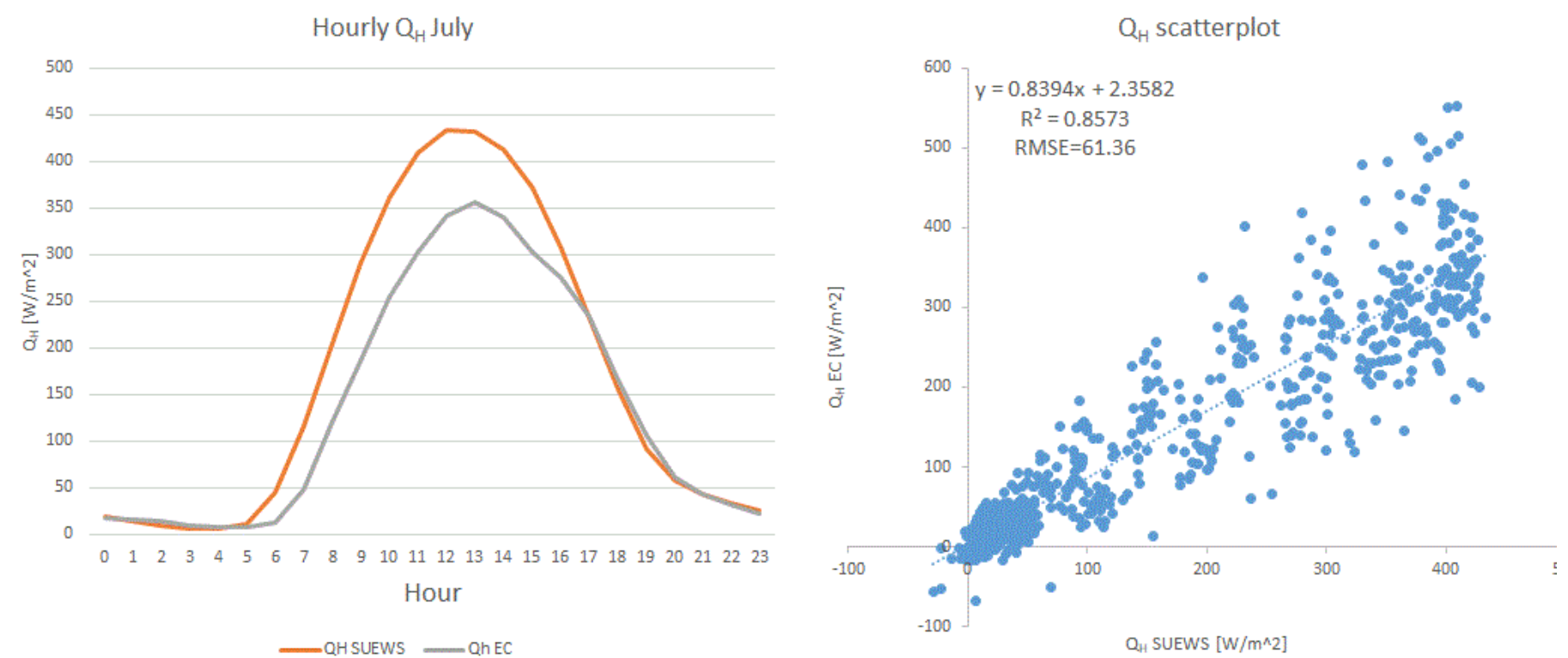

Figure 8 The hourly average of $\mathrm{QH}$ for July on the left and the sensible heat flux.

A similar study in Porto with a warm-summer Mediterranean climate type Csb in Koppen showed differences between urban and suburban areas outside the city [22]. Compared to Heraklion, Porto has a lower average temperature during hot months with more wet winters with an average of $1.237 \mathrm{~mm} /$ year precipitation instead of $500.6 \mathrm{~mm} /$ year for Heraklion. The forcing data were modeled using the Weather Research and Forecasting Model (WRF) and compared with EC tower data. The final RSME of QH for urban areas reaches $85.9 \mathrm{~W} / \mathrm{m}^{2}$ and $49.4 \mathrm{~W} / \mathrm{m}^{2}$ for the suburban area for 1 August -31 December 2014. The results showed a slightly better performance for the model when it is applied in suburban areas. Moreover, the model seemed to perform better in the specific study for measured forcing data.

Another study in Helsinki [47], with humid continental climate type Dfb according to Koppen, took place in two sites, an urban and a suburban area. The results errors for the summertime were close to Porto and Heraklion. The RMSE for QH during summer was $67.1 \mathrm{~W} / \mathrm{m}^{2}$ and 52.9 $\mathrm{W} / \mathrm{m}^{2}$ for the urban and suburban areas, respectively. The forcing data were extracted from EC towers, and the modeled data were compared with fluxes from EC tower. The error for the period of autumn in Helsinki was $38.3 \mathrm{~W} / \mathrm{m}^{2}$ and $27.1 \mathrm{~W} / \mathrm{m}^{2}$ for the urban and suburban areas, respectively. The study at Helsinki showed that the model seems to perform better for the autumn-winter compared to spring-summer.

Even using the basic parameterization and forcing data, the model seems to perform well for different areas. The low requirements of input data make the model suitable for several studies that focus on surface energy balance. 


\section{Results and Discussion}

Following the SUEWS model development and evaluation for Heraklion, the evaluated model is utilized to analyze the impact of NBS on the specific urban area. The NBS that are proposed are mainly linked with greenery and water bodies development. Five different NBS scenarios are simulated and studied:

1. Replacement of pavements with trees

2. Replacement of roofs with grass

3. Replacement of pavements with grass

4. A mixture of replacement of roofs with grass and pavements with trees

5. Replacement of pavements with water bodies

The scenarios mentioned above change the evapotranspiration and the city area's albedo, leading to changes in the energy fluxes. Increasing the city's green areas, the turbulent latent heat flux increases and turbulent sensible heat flux decreases, leading to evaporative cooling. The changes in energy fluxes directly impact the air temperature and relative humidity (see Figure 3 ). The changes are discussed in the following subsections.

\subsection{Replacement of pavements with trees}

The surface cover fractions are changed in the specific scenario versus the baseline conditions tabulated in Table 2 . Three different conditions are examined where different fractions are analyzed, i.e., 10\%, 20\% and $30 \%$ increase of trees. The type of trees used are deciduous trees. The changes of air temperature in $2 \mathrm{~m}$ height in the simulation area when replacing pavements with trees is depicted in Figure 9. The specific figure illustrates the air temperature for two days during the summer period when the urban overheating is present. The diurnal cycles for $\mathrm{QH}$ and QE for two days per each month during the summer period are illustrated in Figure 10 and Figure 11 respectively. The two days cycle is selected to show the diurnal cycle of air temperature, sensible and latent heat fluxes changes. The overall changes on a monthly basis for air temperature, relative humidity and fluxes are tabulated in Table 3.

By replacing the existing pavements with deciduous trees, a reduction of air temperature occurs during the daytime. The decrease of air temperature peaks although it is almost $0.5 \mathrm{~K}$ occurs for all months and for the $20 \%$ replacement of pavements as expected. A steep decrease of the air temperature occurs during nighttime for all months which is almost $1-2 \mathrm{~K}$. The air temperature when trees are inserted peaks faster than the normal (baseline scenario) before midday instead of the baseline scenario that temperature exceeds the trees scenario during the afternoon. As expected, the increase of greenery reduces the 
sensible heat flux peaks during daytime and increases the turbulent latent heat fluxes respectively.

The diurnal cycles of the sensible and latent heat fluxes with the increase of greenery follow closely the baseline patterns for all days in the summer period. The reduction of the sensible heat flux is higher during the daytime for both days and for all summer months and can be among $100-200 \mathrm{~W} / \mathrm{m}^{2}$ in peak hours. During night the decrease of sensible heat flux is not so significant. By increasing the greenery from $10 \%$ to $20 \%$ the decrease of the sensible heat flux during nighttime is negligible.
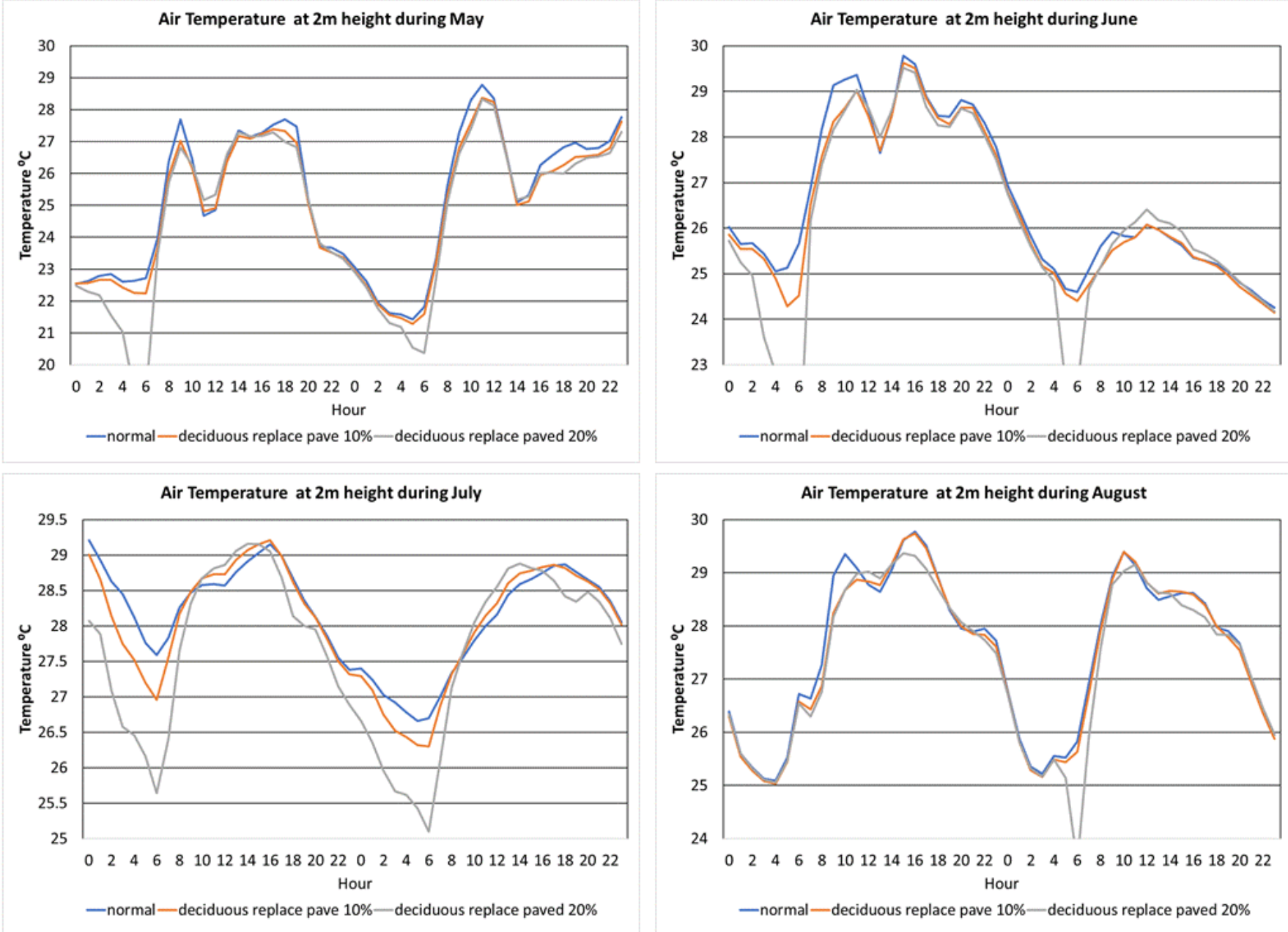

Figure 9 Air temperature for 2 days during May, June, July and August for the replacement of pavements with trees.

A decrease of $\mathrm{Q}^{*}$ and $\Delta \mathrm{Q}$ s is noticed for all months (Table 3). Moreover, there is a decrease of turbulent sensible heat flux from the city to the atmosphere $(\mathrm{QH})$ about 150 to $200 \mathrm{~W} / \mathrm{m}^{2}$ depending the period (Figure 10) due to the other fluxes' changes as explained in Eq. 12. An increase of the turbulent latent heat flux (Figure 11), which is almost equal to the decrease of sensible heat flux, indicates an increase of evapotranspiration around the trees and an increase of the relative 
humidity. When the decrease of $\mathrm{QH}$ is high, the $\mathrm{Q}^{*}$ and $\Delta \mathrm{Q}$ s decrease is low and vice versa. For example, during July the percentage decrease of $\mathrm{QH}$ is the lowest one for both $10 \%$ and $20 \%$ replacement of pavements with greenery. During that month the $\mathrm{Q} *$ and $\Delta \mathrm{Q}$ s have their highest percentage of changes. This is in accordance with Eq. 12. The reduction of the $Q^{*}$ is attributed to the increase of the surface covers' albedo when trees replace the pavements. The reduction of $Q^{*}$ follows the percentage of reduction of the heat storage in the are $\alpha$ for all months. The increase of greenery has a direct impact on the increase of latent turbulent heat flux as expected. The percentage of increase of QE is almost the same for all months and is on average $106 \%$ for $10 \%$ increase of greenery and $165 \%$ for $20 \%$ increase of greenery. Therefore, the presence of greenery significantly influences the fluxes' energy balance which explains the increase of relative humidity and the slight decrease of the air temperature.
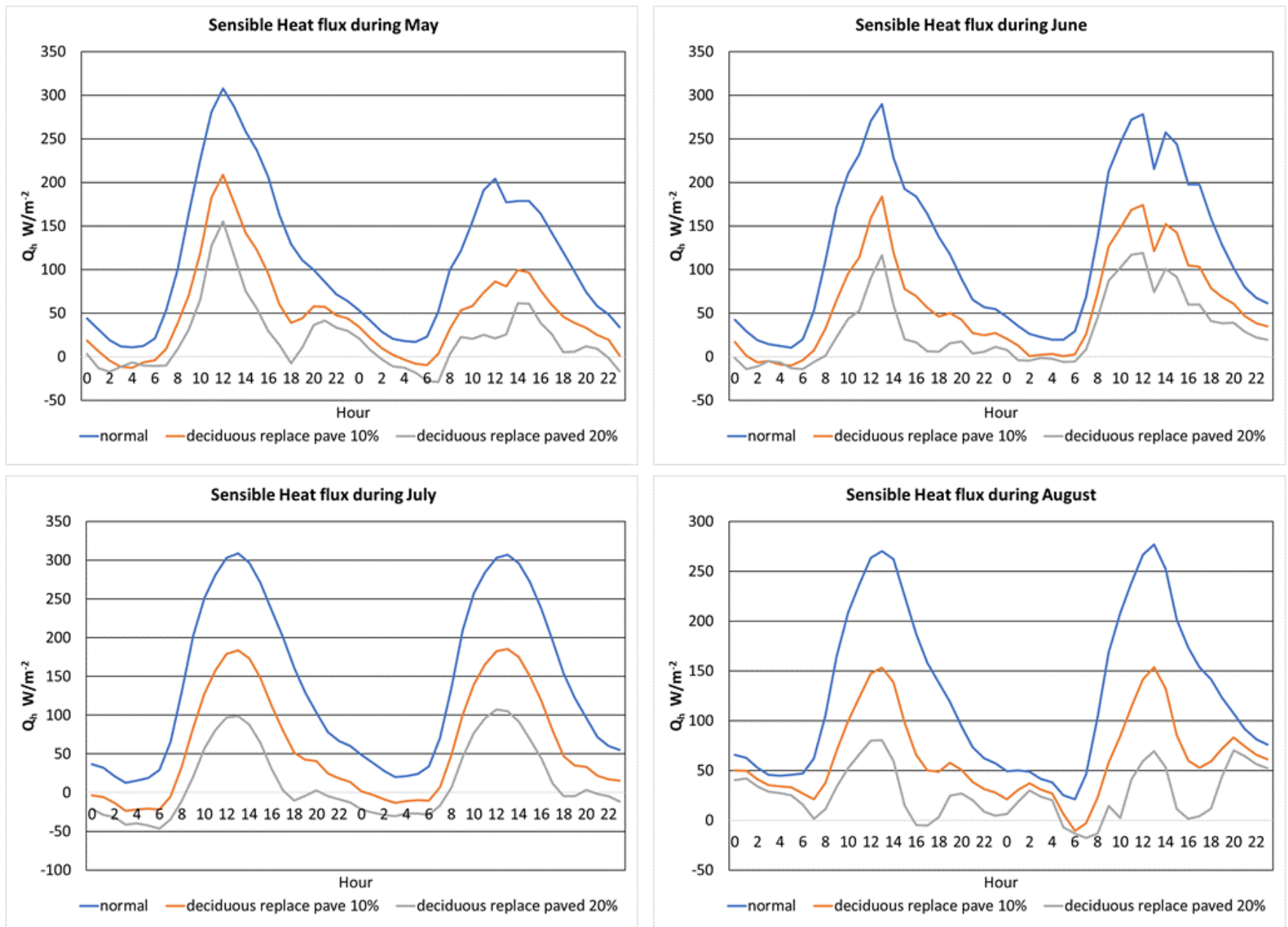

Figure 10 Sensible heat flux for 2 days during May, June, July and August for the replacement of pavements with trees. 

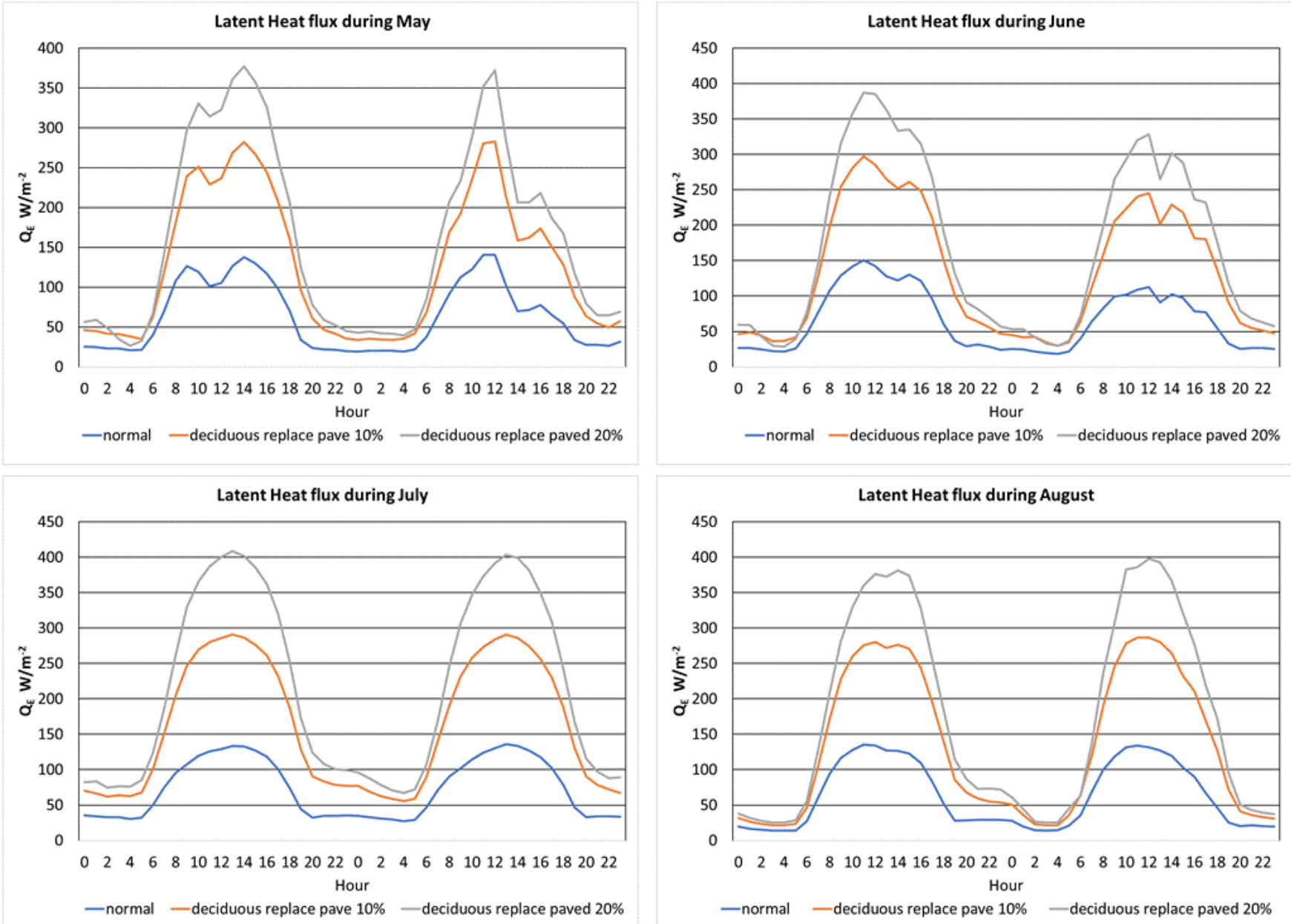

Figure 11 Turbulent Latent heat flux for 2 days during May, June, July and August for the replacement of pavements with trees.

Table 3 Percentage of changes for all fluxes and for air temperature and relative humidity during the daytime on a monthly basis.

\begin{tabular}{|l|c|c|c|c|c|c|}
\hline Month & \multicolumn{7}{|l|}{ Deciduous green trees replace pavements 10\% } \\
\hline & $\mathrm{Q}^{*}$ & $\Delta \mathrm{Qs}$ & $\mathrm{QH}$ & $\mathrm{QE}$ & Tair & $\mathrm{RH}$ \\
\hline May & $-0.88 \%$ & $-4.51 \%$ & $-191.44 \%$ & $103.80 \%$ & $-0.25 \%$ & $4.24 \%$ \\
\hline June & $-0.95 \%$ & $-4.43 \%$ & $-84.07 \%$ & $106.27 \%$ & $-0.47 \%$ & $6.07 \%$ \\
\hline July & $-3.75 \%$ & $-16.92 \%$ & $-58.72 \%$ & $104.49 \%$ & $-0.38 \%$ & $5.23 \%$ \\
\hline August & $-1.16 \%$ & $-2.21 \%$ & $-63.96 \%$ & $108.62 \%$ & $-0.10 \%$ & $3.40 \%$ \\
\hline \multicolumn{7}{|c|}{ Deciduous green trees replace pavements $\mathbf{2 0} \%$} \\
\hline May & $-1.77 \%$ & $-8.84 \%$ & $-329.88 \%$ & $162.70 \%$ & $-0.30 \%$ & $13.56 \%$ \\
\hline June & $-1.90 \%$ & $-8.56 \%$ & $-120.15 \%$ & $163.74 \%$ & $-1.20 \%$ & $23.54 \%$ \\
\hline July & $-7.50 \%$ & $-33.28 \%$ & $-90.28 \%$ & $162.25 \%$ & $-0.77 \%$ & $18.03 \%$ \\
\hline August & $-2.45 \%$ & $-4.30 \%$ & $-100.24 \%$ & $169.45 \%$ & $-0.62 \%$ & $14.08 \%$ \\
\hline
\end{tabular}




\subsection{Replacement of roofs with green roofs}

In this scenario, the roofs of the city area of Heraklion are replaced with green roofs. Although green roofs have a different behavior than grass, the species used for green roofs in the area of Greece are local species similar to ones cultivated using ground soil. Moreover, in the scale that the scenario is analyzed the presence of greenery in rooftops changes the balance among the various fluxes as we can see from the results.

To simulate this scenario, the concrete roofs are replaced with grass. Three different fractions are examined in this scenario, i.e., $10 \%, 20 \%$ and $30 \%$ replacement of roofs' area with grass.

The changes in air temperature at $2 \mathrm{~m}$ height for two days in the summer period are depicted in Figure 12, while the changes in sensible and turbulent latent heat flux are illustrated in Figure 13 and Figure 14 respectively. The air temperature peaks are decreasing while the percentage of green roofs is increasing. During peak daytime hours, the air temperature decrease can reach up to $1-1.5 \mathrm{~K}$. The diurnal fluctuations of the air temperature do not change with the presence of the green roofs. Also during the early night hours (e.g. between 22:00 to $4: 00$ ) the temperature is not significantly decreased with 10 or $20 \%$ increase of greenery while there is a significant decrease with $30 \%$ replacement of roofs with greenery. On the other hand, we can notice a considerable decrease of air temperature between 4:00-8:00.

The sensible heat flux is decreased as depicted in Figure 13 especially during daytime. During night the levels of sensible heat flux are not changed in a great extent. Another critical aspect is the fact that with the presence of greenery the lower values of sensible heat flux occur during late afternoon which is very important for the urban context.

Again, the increase of the turbulent latent heat flux (Figure 14) is present in this scenario, from $150 \mathrm{~W} / \mathrm{m}^{2}$ for May to $350 \mathrm{~W} / \mathrm{m}^{2}$ for July for the scenario of changing $10 \%$. This difference increases along with the rise of green roofs area, while a significant increase of relative humidity is noticed that can reach $33.32 \%$.

The replacement of roofs with grass reduces the $Q$ * since the surface albedo increases (Table 4). Moreover, the changes of air temperature at $2 \mathrm{~m}$ height are illustrated, showing a significant decrease for this scenario that during daytime can reach up to 1-1.5K. This is also tabulated in Table 4 where for daytime during May a decrease of air temperature of $0,8 \%$ is noticed while in July and August this percentage reaches $2.2 \%$ and $1.8 \%$ respectively. The highest decrease is pinpointed when a $30 \%$ increase in grass is performed. The decrease of sensible heat flux due to the replacement of the roofs with green roofs is in accordance with similar previous publications that studied the performance of green roofs and their urban heat mitigation potential [18]. 
Table 4 Percentage of changes for all fluxes and for air temperature and relative humidity during the daytime on a monthly basis for the replacement of roofs.

\begin{tabular}{|c|c|c|c|c|c|c|}
\hline \multirow[t]{2}{*}{ Month } & \multicolumn{6}{|c|}{ Green roofs replace existing roofs $10 \%$} \\
\hline & $Q^{*}$ & $\Delta \mathrm{Qs}$ & $\mathrm{QH}$ & $\mathrm{QE}$ & Tair & $\mathrm{RH}$ \\
\hline May & $-1.12 \%$ & $-2.73 \%$ & $-32.90 \%$ & $70.37 \%$ & $-0.68 \%$ & $3.81 \%$ \\
\hline June & $-1.10 \%$ & $-3.20 \%$ & $-52.12 \%$ & $81.92 \%$ & $-0.94 \%$ & $6.91 \%$ \\
\hline July & $-4.32 \%$ & $-9.75 \%$ & $-44.78 \%$ & $79.99 \%$ & $-0.84 \%$ & $5.67 \%$ \\
\hline \multirow[t]{3}{*}{ August } & $-1.35 \%$ & $-1.40 \%$ & $-43.09 \%$ & $79.90 \%$ & $-0.52 \%$ & $3.07 \%$ \\
\hline & \multicolumn{6}{|c|}{ Green roofs replace existing roofs $20 \%$} \\
\hline & $Q^{*}$ & $\Delta \mathrm{QS}$ & $\mathrm{QH}$ & $\mathrm{QE}$ & Tair & $\mathrm{RH}$ \\
\hline May & $-2.25 \%$ & $-5.32 \%$ & $-145.35 \%$ & $141.49 \%$ & $0.43 \%$ & $11.79 \%$ \\
\hline June & $-2.20 \%$ & $-6.20 \%$ & $-105.34 \%$ & $143.42 \%$ & $-0.85 \%$ & $21.85 \%$ \\
\hline July & $-8.58 \%$ & $-19.14 \%$ & $-77.79 \%$ & $139.11 \%$ & $-0.64 \%$ & $16.78 \%$ \\
\hline \multirow[t]{3}{*}{ August } & $-2.83 \%$ & $-2.71 \%$ & $-81.23 \%$ & $143.33 \%$ & $-0.57 \%$ & $11.67 \%$ \\
\hline & \multicolumn{6}{|c|}{ Green roofs replace existing roofs $30 \%$} \\
\hline & $Q^{*}$ & $\Delta \mathrm{Qs}$ & $\mathrm{QH}$ & QE & Tair & $\mathrm{RH}$ \\
\hline May & $-3.37 \%$ & $-7.78 \%$ & $-303.30 \%$ & $193.89 \%$ & $-0.83 \%$ & $19.01 \%$ \\
\hline June & $-3.30 \%$ & $-8.99 \%$ & $-142.67 \%$ & $187.28 \%$ & $-2.22 \%$ & $32.07 \%$ \\
\hline July & $-12.85 \%$ & $-28.11 \%$ & $-102.26 \%$ & $182.29 \%$ & $-1.82 \%$ & $24.62 \%$ \\
\hline August & $-4.31 \%$ & $-3.94 \%$ & $-109.92 \%$ & $188.83 \%$ & $-1.62 \%$ & $18.69 \%$ \\
\hline
\end{tabular}
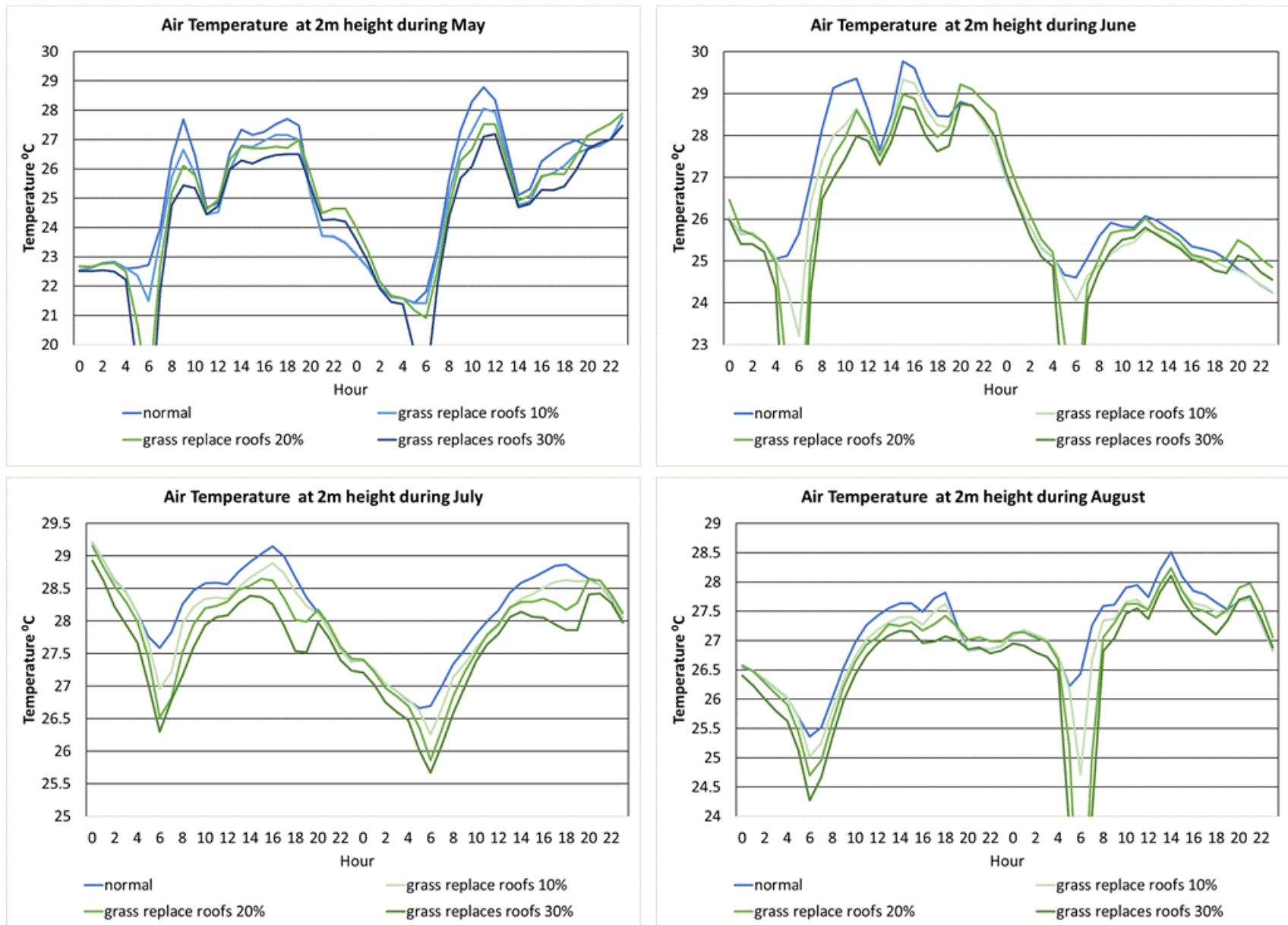

Figure 12 Air temperature for 2 days during May, June, July and August for the replacement of roofs with green roofs. 

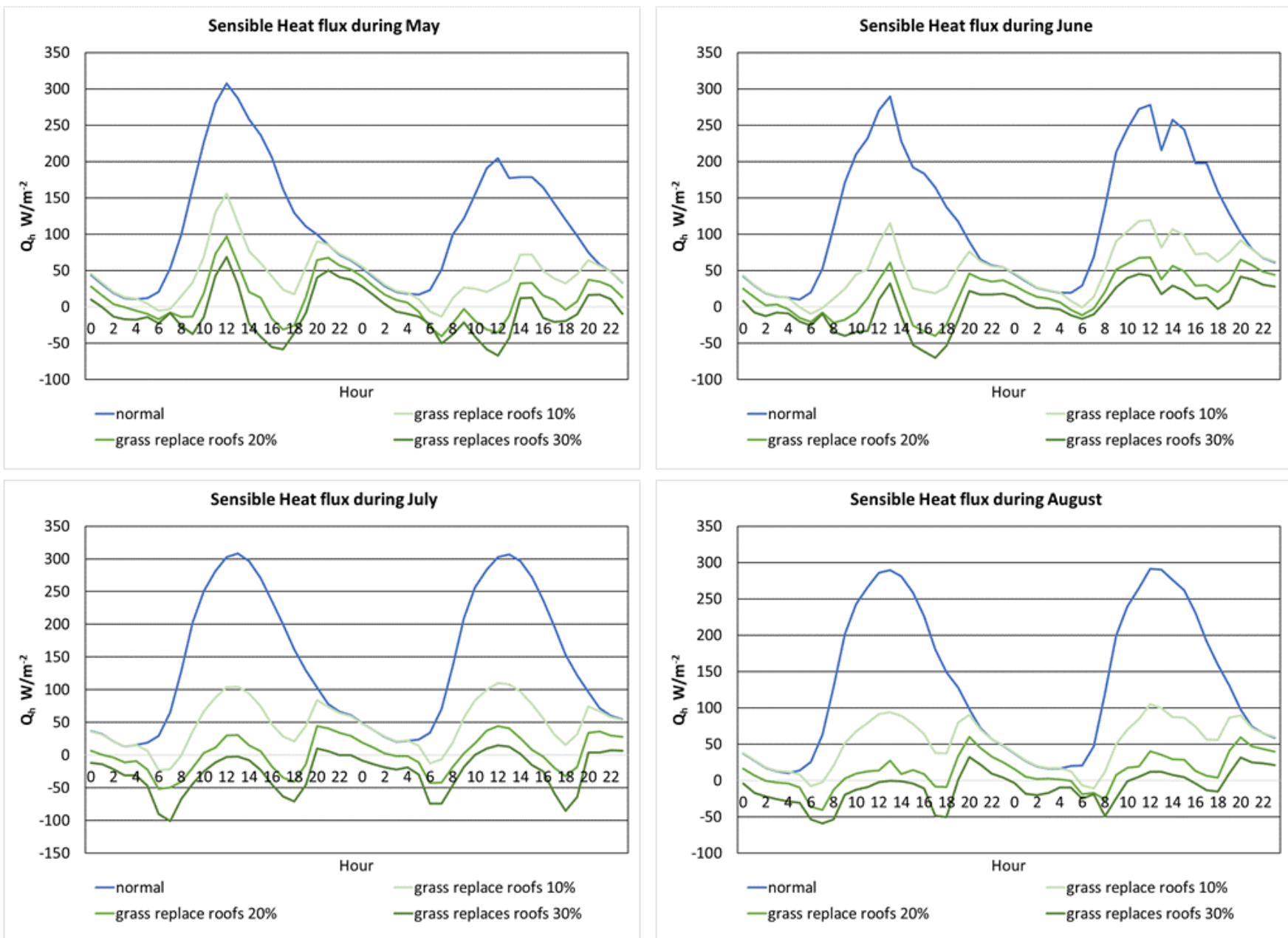

Figure 13 Sensible heat flux for 2 days during May, June, July and August for the replacement of roofs with green roofs. 

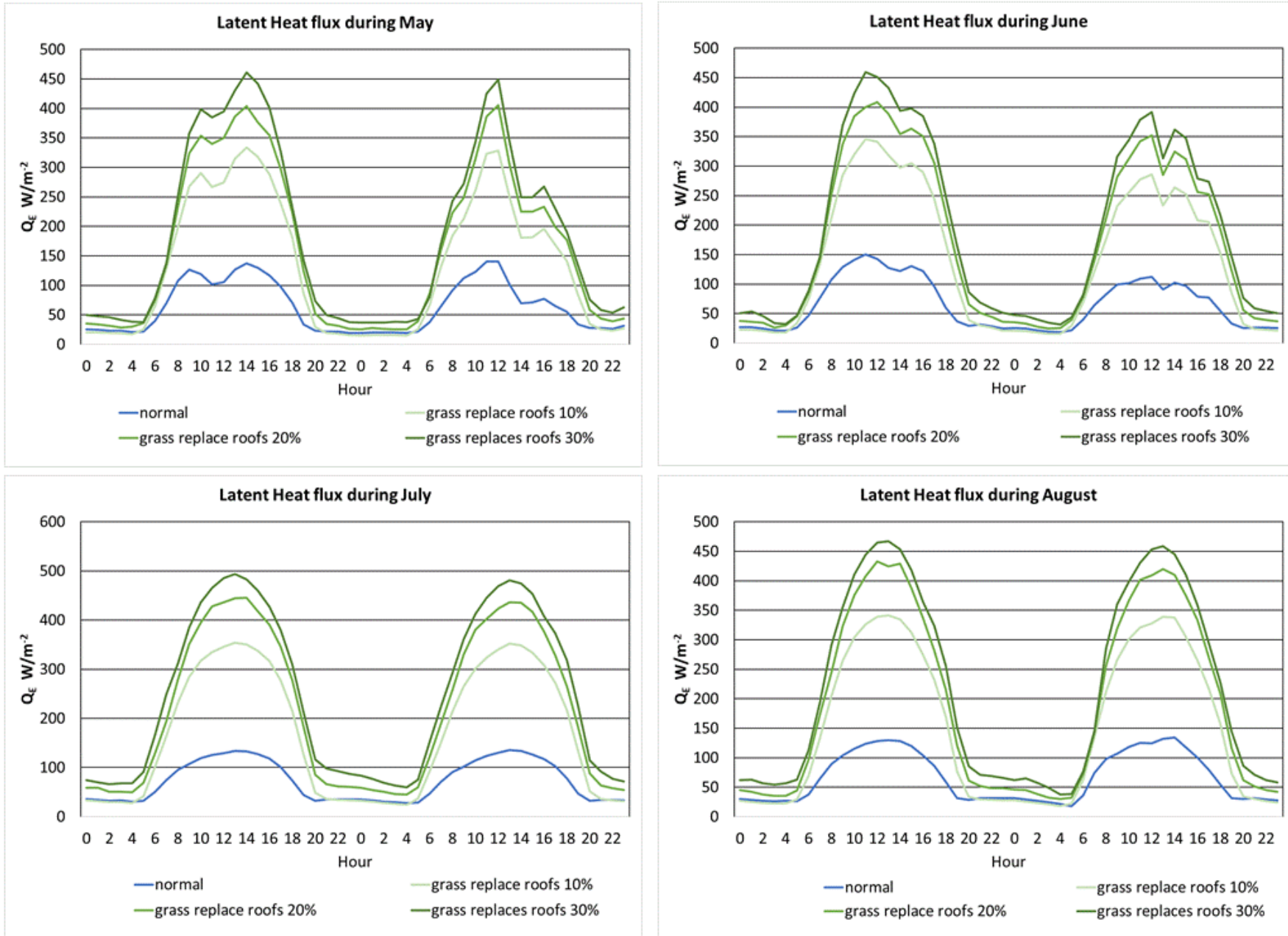

Figure 14 Turbulent latent heat flux for 2 days during May, June, July and August for the replacement of roofs with green roofs.

\subsection{Replacement of pavements with grass}

In this specific scenario, three alternatives are examined, i.e., $10 \%, 20 \%$ and $30 \%$ replacement of pavements with grass. The impact of the replacement of pavement with grass on the air temperature is depicted in Figure 15. The decrease of air temperature reaches almost $1 \mathrm{~K}$ for $30 \%$ replacement of grass for July. The fluxes differences on a monthly basis are tabulated in Table 5. The reduction of QH (Figure 16) is attributed to the overall balance of the fluxes based on Eq. 12, and it is mainly due to the significant increase of the turbulent latent heat flux and the decrease of the net wave radiation for the box of Figure 2. Again, the results are similar to the previous case of replacing roofs with grass. The turbulent latent heat flux increases between 200 and $400 \mathrm{~W} / \mathrm{m}^{2}$ proportionally to the replacement of grass (Figure 17), and the sensible heat is decreased between 100 and $250 \mathrm{~W} / \mathrm{m}^{2}$ (Figure 16). In almost all cases a slight increase of relative humidity is noticed. 

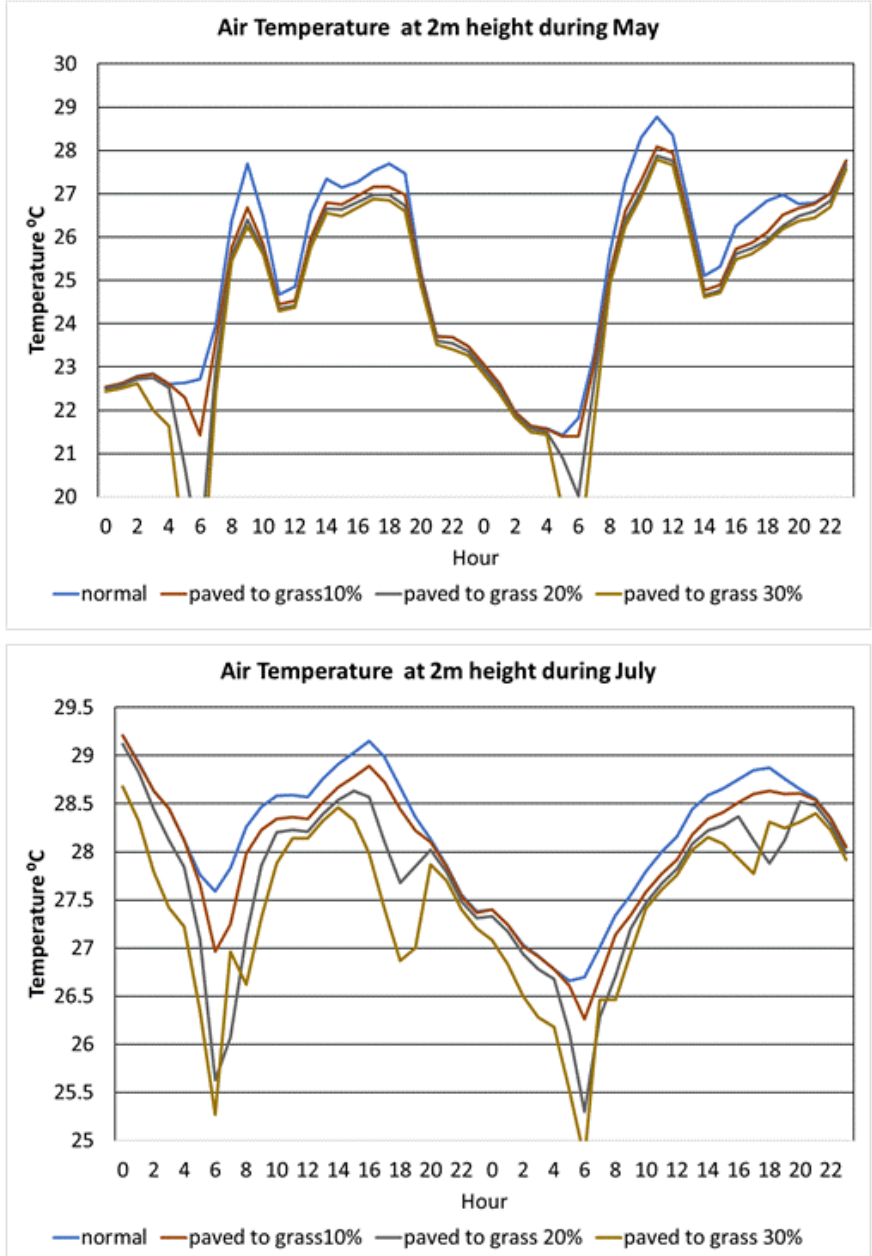
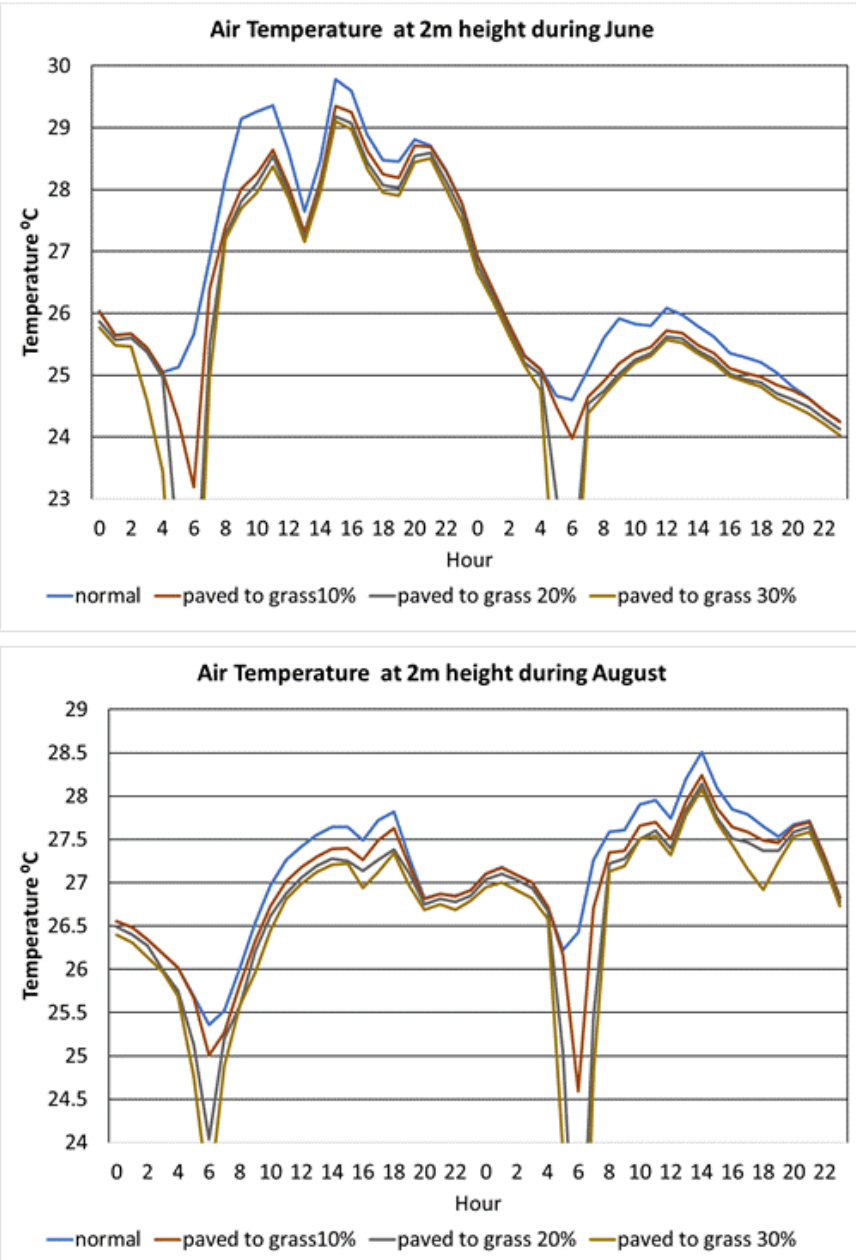

Figure 15 Air temperature for 2 days during May, June, July and August for the replacement of pavements with grass. 

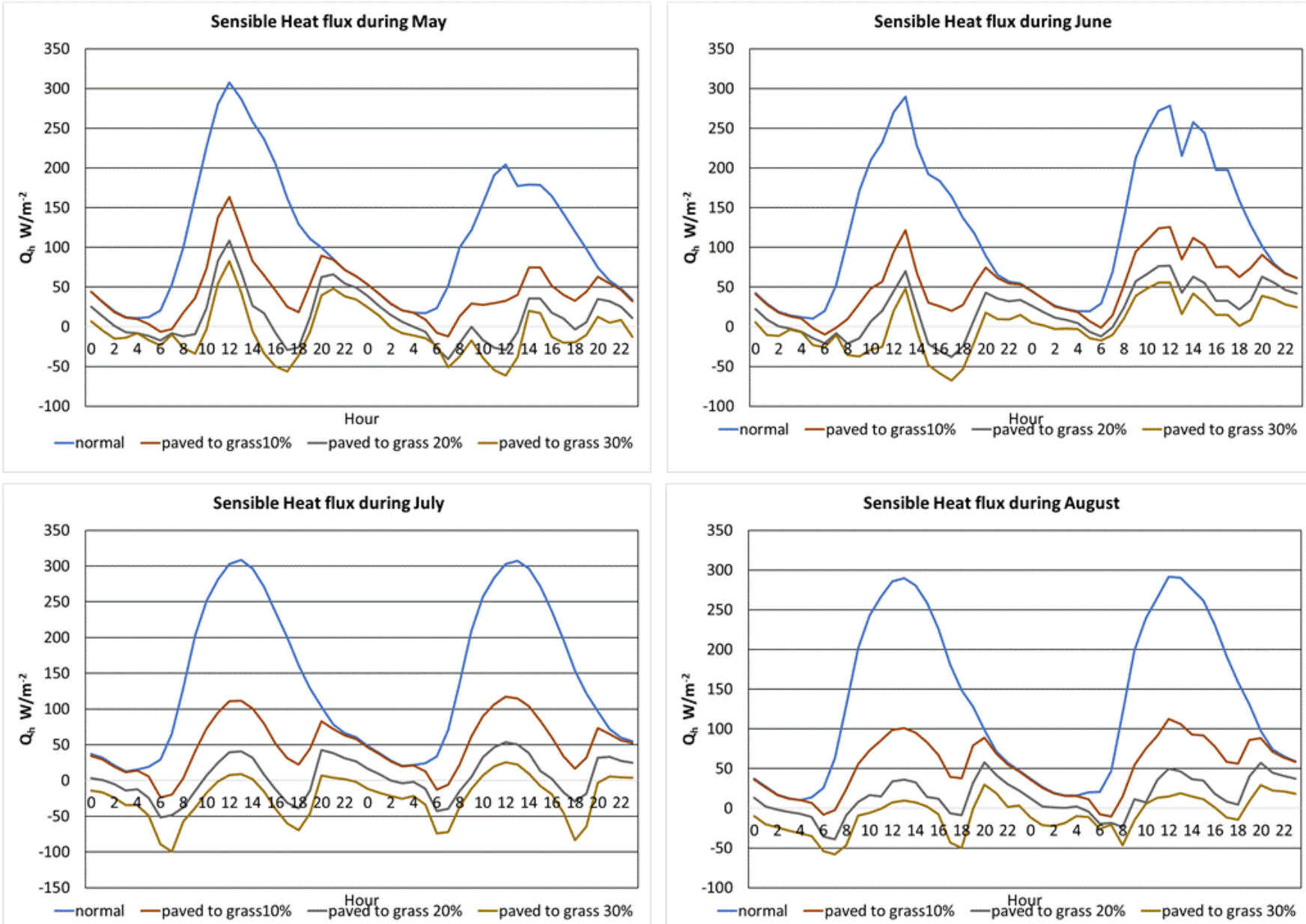

Figure 16 Sensible heat flux for 2 days during May, June, July and August for the replacement of pavements with grass.

Table 5 Percentage of changes for all fluxes and for air temperature and relative humidity during the daytime on a monthly basis for the replacement of pavements with grass.

\begin{tabular}{|c|c|c|c|c|c|c|}
\hline \multirow[t]{2}{*}{ Month } & \multicolumn{6}{|c|}{ Grass replace pavements $10 \%$} \\
\hline & $Q^{*}$ & $\Delta \mathrm{Qs}$ & $\mathrm{QH}$ & $\mathrm{QE}$ & Tair & $\mathrm{RH}$ \\
\hline May & $-0.92 \%$ & $-4.76 \%$ & $-41.44 \%$ & $71.66 \%$ & $-0.71 \%$ & $3.73 \%$ \\
\hline June & $-0.94 \%$ & $-4.81 \%$ & $-54.75 \%$ & $83.47 \%$ & $-0.96 \%$ & $6.65 \%$ \\
\hline July & $-3.55 \%$ & $-17.53 \%$ & $-45.38 \%$ & $81.62 \%$ & $-0.86 \%$ & $5.47 \%$ \\
\hline \multirow[t]{3}{*}{ August } & $-1.09 \%$ & $-2.34 \%$ & $-43.99 \%$ & $81.28 \%$ & $-0.55 \%$ & $3.02 \%$ \\
\hline & \multicolumn{6}{|c|}{ Grass replace pavements $20 \%$} \\
\hline & $\mathrm{Q}^{*}$ & $\Delta \mathrm{Qs}$ & $\mathrm{QH}$ & $\mathrm{QE}$ & Tair & $\mathrm{RH}$ \\
\hline May & $-1.84 \%$ & $-9.27 \%$ & $-157.34 \%$ & $144.44 \%$ & $-1.37 \%$ & $7.82 \%$ \\
\hline June & $-1.88 \%$ & $-9.25 \%$ & $-109.00 \%$ & $146.50 \%$ & $-1.85 \%$ & $15.88 \%$ \\
\hline July & $-7.09 \%$ & $-34.30 \%$ & $-79.21 \%$ & $142.65 \%$ & $-1.58 \%$ & $12.78 \%$ \\
\hline \multirow[t]{3}{*}{ August } & $-2.31 \%$ & $-4.52 \%$ & $-83.04 \%$ & $146.40 \%$ & $-1.26 \%$ & $9.61 \%$ \\
\hline & \multicolumn{6}{|c|}{ Grass replace pavements $30 \%$} \\
\hline & $Q^{*}$ & $\Delta \mathrm{Qs}$ & $\mathrm{QH}$ & $\mathrm{QE}$ & Tair & $\mathrm{RH}$ \\
\hline May & $-2.76 \%$ & $-13.51 \%$ & $-313.03 \%$ & $197.33 \%$ & $-2.02 \%$ & $12.27 \%$ \\
\hline June & $-2.82 \%$ & $-13.32 \%$ & $-144.70 \%$ & $191.02 \%$ & $-2.67 \%$ & $22.63 \%$ \\
\hline July & $-10.63 \%$ & $-50.26 \%$ & $-103.44 \%$ & $186.39 \%$ & $-2.18 \%$ & $17.32 \%$ \\
\hline August & $-3.53 \%$ & $-6.53 \%$ & $-111.86 \%$ & $192.87 \%$ & $-1.99 \%$ & $16.80 \%$ \\
\hline
\end{tabular}



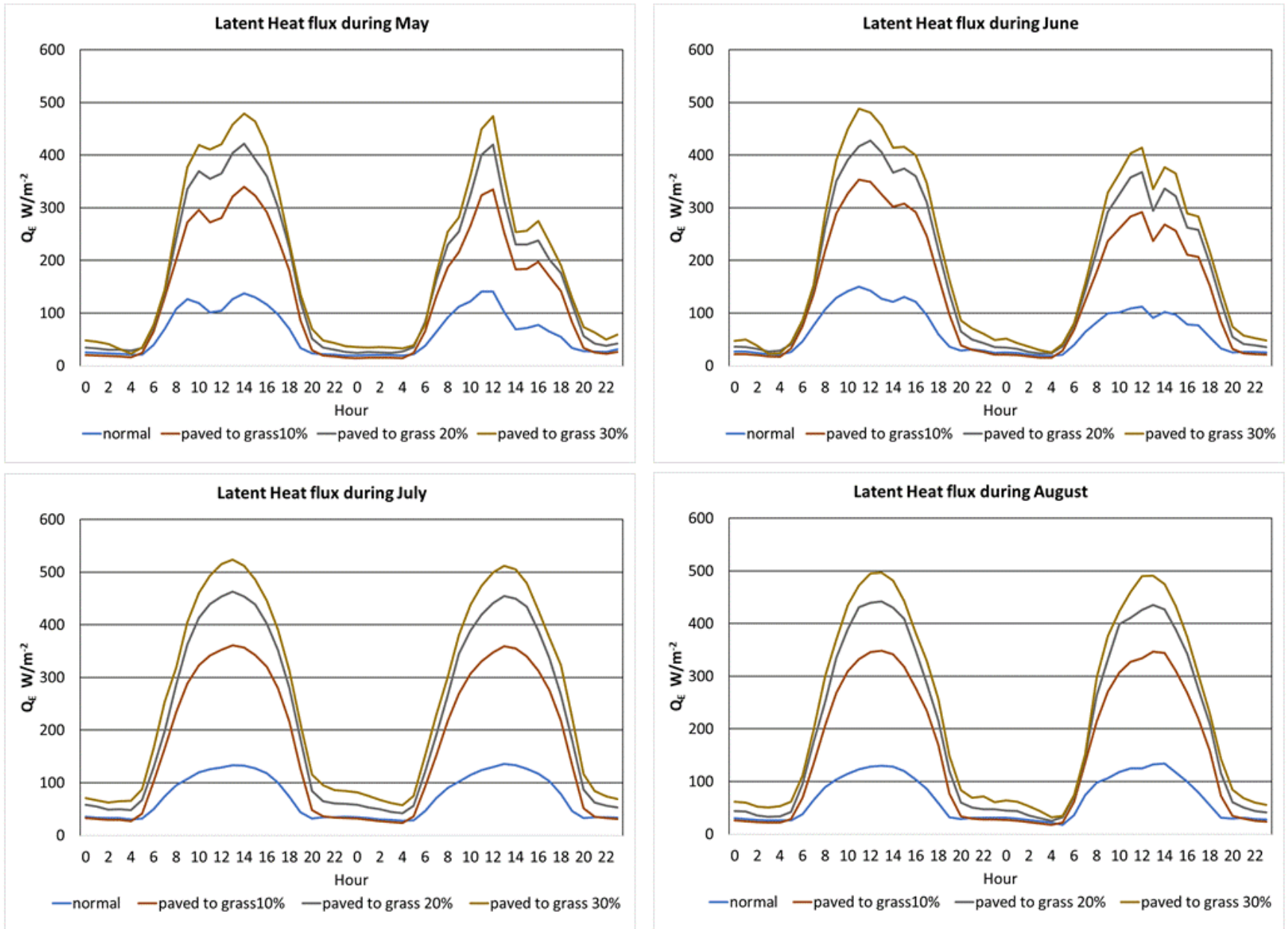

Figure 17 Latent heat flux for 2 days during May, June, July and August for the replacement of pavements with grass.

\subsection{Replacement of pavements with trees and grass and roofs with grass}

The specific scenario is a combination of two of the above and allows the study of the interrelations between the various NBS alternatives. The temperature decrease also occurs in this scenario and exceeds $1 \mathrm{~K}$ during daytime, as depicted in Figure 18. The percentage of change for the air temperature monthly and during the daytime is greater than $2 \%$ except for May, which shows a smaller decrease. The decrease of $\mathrm{Q}^{*}$ is slightly higher than the one noticed when the roofs are replaced with grass due to the reduction of surface albedo for replacing higher percentage area of buildings and paved using higher albedo fractions (Table 6). The turbulent latent heat flux has the same behavior with the 1st scenario where the pavements are replaced with trees and grass, and it is in accordance with the replacement of roofs with grass. The decrease of the $\mathrm{QH}$ in Figure 19 is explained by the increase of the turbulent latent heat flux in Figure 20. The results are similar with scenarios 2 and 3, when grass replaces $30 \%$ of roof or pavements. This 
is attributed to the fact that trees are combined with grass replacing paved and roofs. A very small air temperature decrease occurs when trees and grass replace pavements and roofs respectively, as depicted in Figure 18. The temperature difference exceeds $1 \mathrm{~K}$.
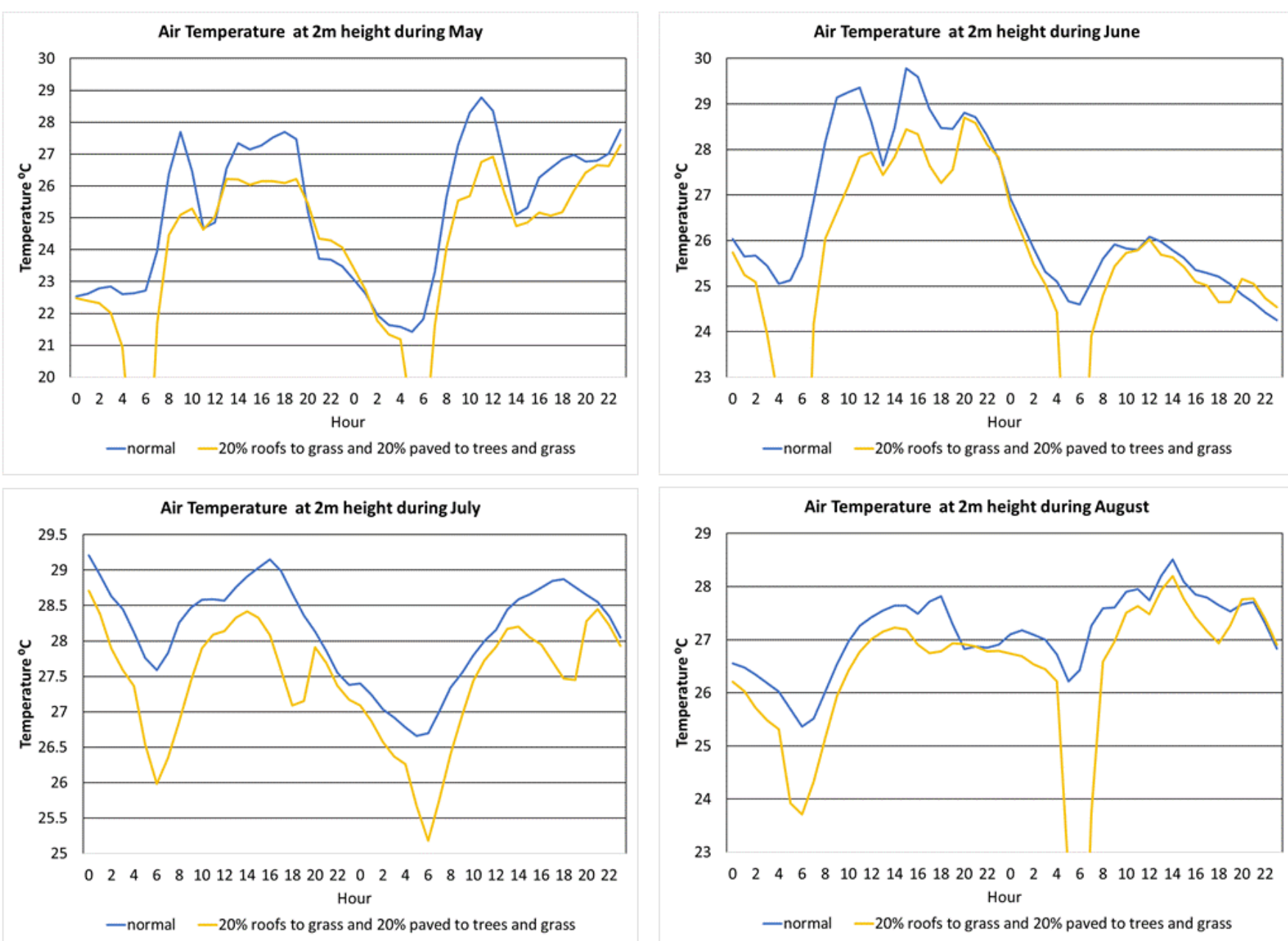

Figure 18 Air temperature for 2 days during May, June, July and August for the replacement of pavements with trees and grass and roofs with grass. 
Table 6 Percentage of changes for all fluxes and for air temperature and relative humidity during the daytime on a monthly basis for the replacement of pavements with trees and roofs with grass.

\begin{tabular}{|l|c|c|c|c|c|c|}
\hline Month & \multicolumn{6}{|c|}{ Grass replace roofs 20\% and pavement 10\%, trees replace pavements 10\% } \\
\hline & $\mathrm{Q}^{*}$ & $\Delta \mathrm{QS}$ & $\mathrm{QH}$ & $\mathrm{QE}$ & Tair & $\mathrm{RH}$ \\
\hline May & $-3.51 \%$ & $-13.22 \%$ & $-328.26 \%$ & $206.59 \%$ & $-1.07 \%$ & $26.77 \%$ \\
\hline June & $-3.43 \%$ & $-13.02 \%$ & $-148.99 \%$ & $197.64 \%$ & $-2.84 \%$ & $42.88 \%$ \\
\hline July & $-13.34 \%$ & $-49.47 \%$ & $-107.42 \%$ & $192.83 \%$ & $-2.17 \%$ & $32.97 \%$ \\
\hline August & $-4.46 \%$ & $-6.31 \%$ & $-116.59 \%$ & $199.59 \%$ & $-2.11 \%$ & $26.26 \%$ \\
\hline
\end{tabular}
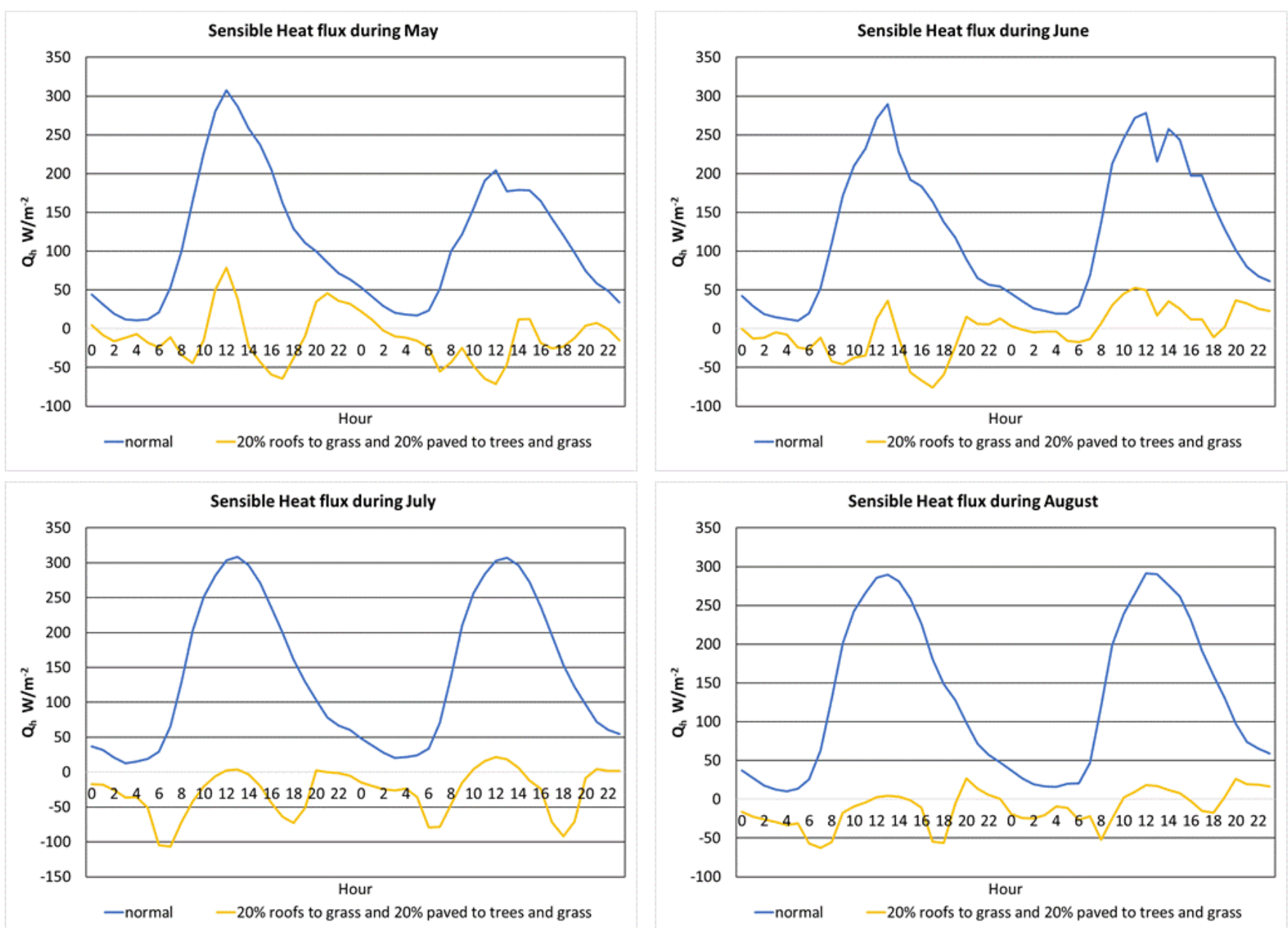

Figure 19 Sensible heat fluxes for 2 days during May, June, July and August for the replacement of pavements with trees and grass and roofs with grass. 

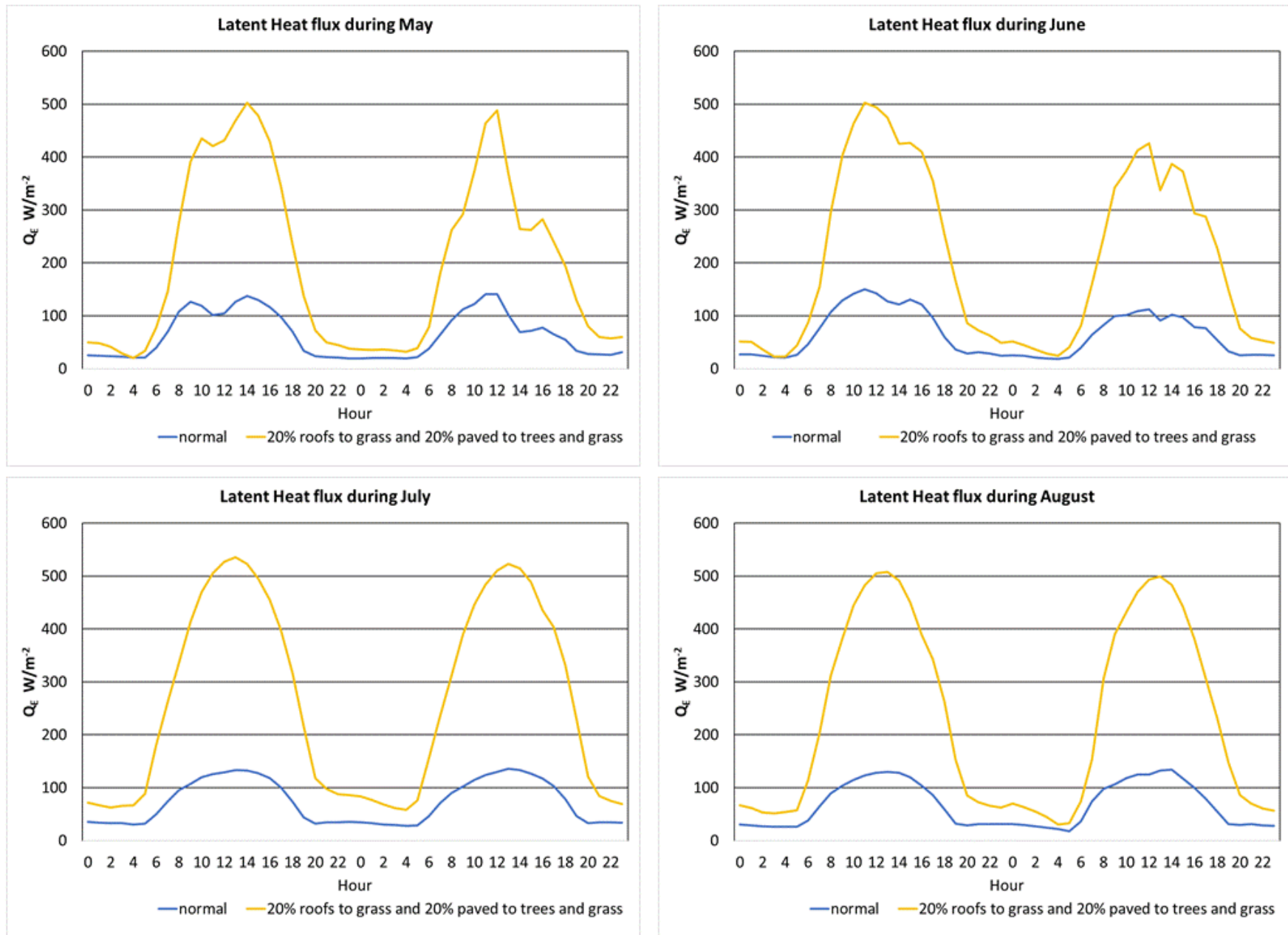

Figure $\mathbf{2 0}$ Latent heat fluxes for 2 days during May, June, July and August for the replacement of pavements with trees and grass and roofs with grass.

\subsection{Replacement of pavements with water}

Although replacing pavements with water bodies is very difficult to be applied in the specific site, the changes that occur are examined. The air temperature during two days is depicted in Figure 21, the sensible heat flux in Figure 22 and the turbulent latent heat flux in Figure 23. The fluxes differences on a monthly basis are tabulated in Table 7. A negligible air temperature decrease is noticed when water bodies are used during daytime. Also during July, the differences are higher, as depicted in Table 7. The $\mathrm{Q}^{*}$ is increased due to the decrease in water albedo versus the pavements. The same occurs for QE as expected, and during daytime evaporation is increased, about $40 \mathrm{~W} / \mathrm{m}^{2}$ for May, the $\mathrm{RH}$ is increased by $1.09 \%$ due to $\mathrm{QE}$ increase. A decrease occurs for $\mathrm{QH}$ over $100 \mathrm{~W} / \mathrm{m}^{2}$, almost the same amount of QE rise, for all months based on the Eq. 12. 
Table 7 Percentage of changes for all fluxes and for air temperature and relative humidity during the daytime on a monthly basis for the replacement of pavements with water.

\begin{tabular}{|l|c|c|c|c|c|c|}
\hline Month & \multicolumn{6}{|l|}{ Water bodies replace pavements 10\% } \\
\hline & $\mathrm{Q}^{*}$ & $\Delta \mathrm{Qs}$ & $\mathrm{QH}$ & $\mathrm{QE}$ & Tair & $\mathrm{RH}$ \\
\hline May & $0.00 \%$ & $-1.41 \%$ & $-82.89 \%$ & $48.24 \%$ & $-0.29 \%$ & $0.96 \%$ \\
\hline June & $0.00 \%$ & $-2.45 \%$ & $-38.36 \%$ & $40.26 \%$ & $-0.25 \%$ & $0.92 \%$ \\
\hline July & $0.00 \%$ & $-4.62 \%$ & $-21.33 \%$ & $39.56 \%$ & $-0.24 \%$ & $1.09 \%$ \\
\hline August & $0.13 \%$ & $-0.84 \%$ & $-24.79 \%$ & $42.45 \%$ & $-0.17 \%$ & $0.63 \%$ \\
\hline
\end{tabular}
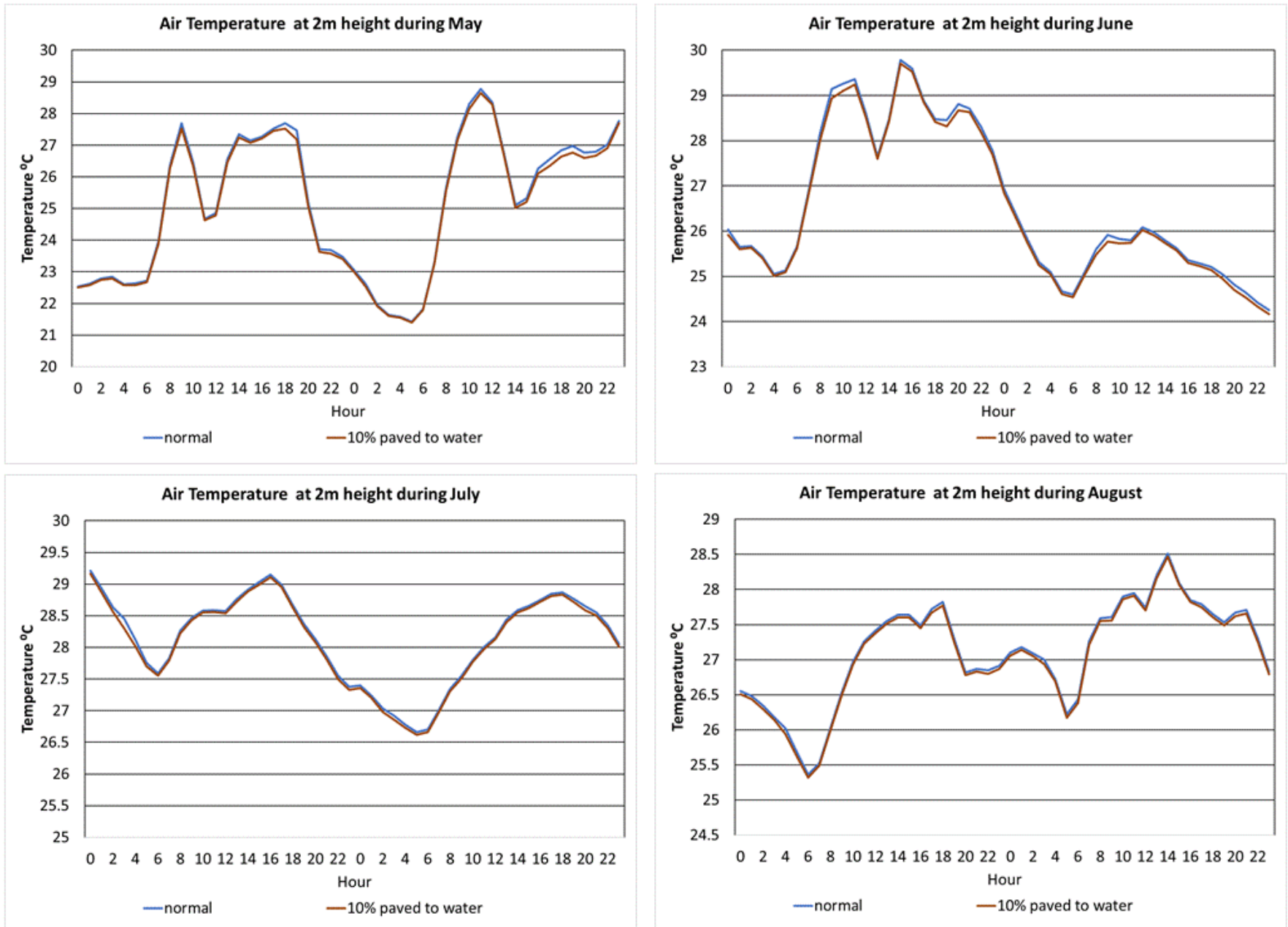

Figure 21 Air temperature for 2 days during May, June, July and August for the replacement of pavements with water.

The NBS scenarios simulation results using SUEWS model shows that albedo has a considerable impact on the net-all wave radiation as expected and seems to be a critical parameter when urban overheating mitigation measures are adopted. The application of NBS in the specific site shows that for all cases, i.e., green infrastructure or water bodies, the air temperature at $2 \mathrm{~m}$ height is reduced versus the baseline. The percentage of replacement also plays a critical role in the improvement of climatic conditions at the site. Moreover, the lower the $\mathrm{K}_{\uparrow}$ the higher the $\mathrm{Q}^{*}$ and $\triangle \mathrm{QS}$ are the energy that is trapped inside the buildings. 

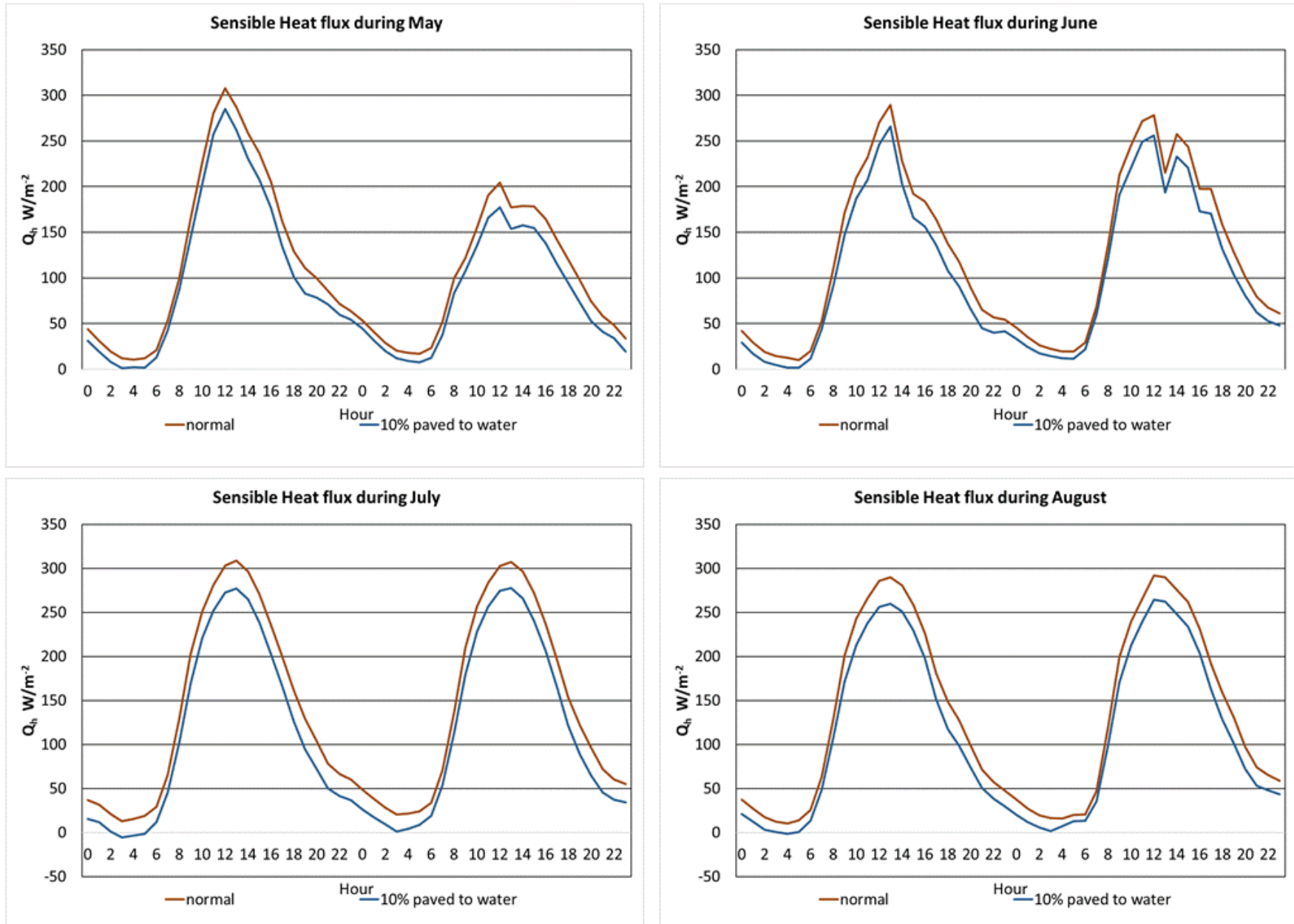

Figure 22 Sensible heat flux for 2 days during May, June, July and August for the replacement of pavements with water.

Since the version of the model we use does not allow to change the pavements' albedo, the interrelation of both highly reflective materials with NBS is not possible. Nevertheless, it should be noted that although with the replacement of pavements with trees, the albedo reduces, the air temperature at $2 \mathrm{~m}$ high is lower than the baseline. Therefore, incorporating highly reflective materials and green infrastructure will have a significant impact on reducing air temperature and surface temperature. An interesting finding is the impact of grass on the air temperature and relative humidity. The selection of the most appropriate solutions should consider the relative humidity of the air in the site to not create discomfort due to the increase of relative humidity. The grass seems to positively impact lowering air temperature without changing the relative humidity of the air significantly. Concerning water bodies, it is well recognized that they contribute to the decrease in air temperature, but relative humidity changes are considerable. 

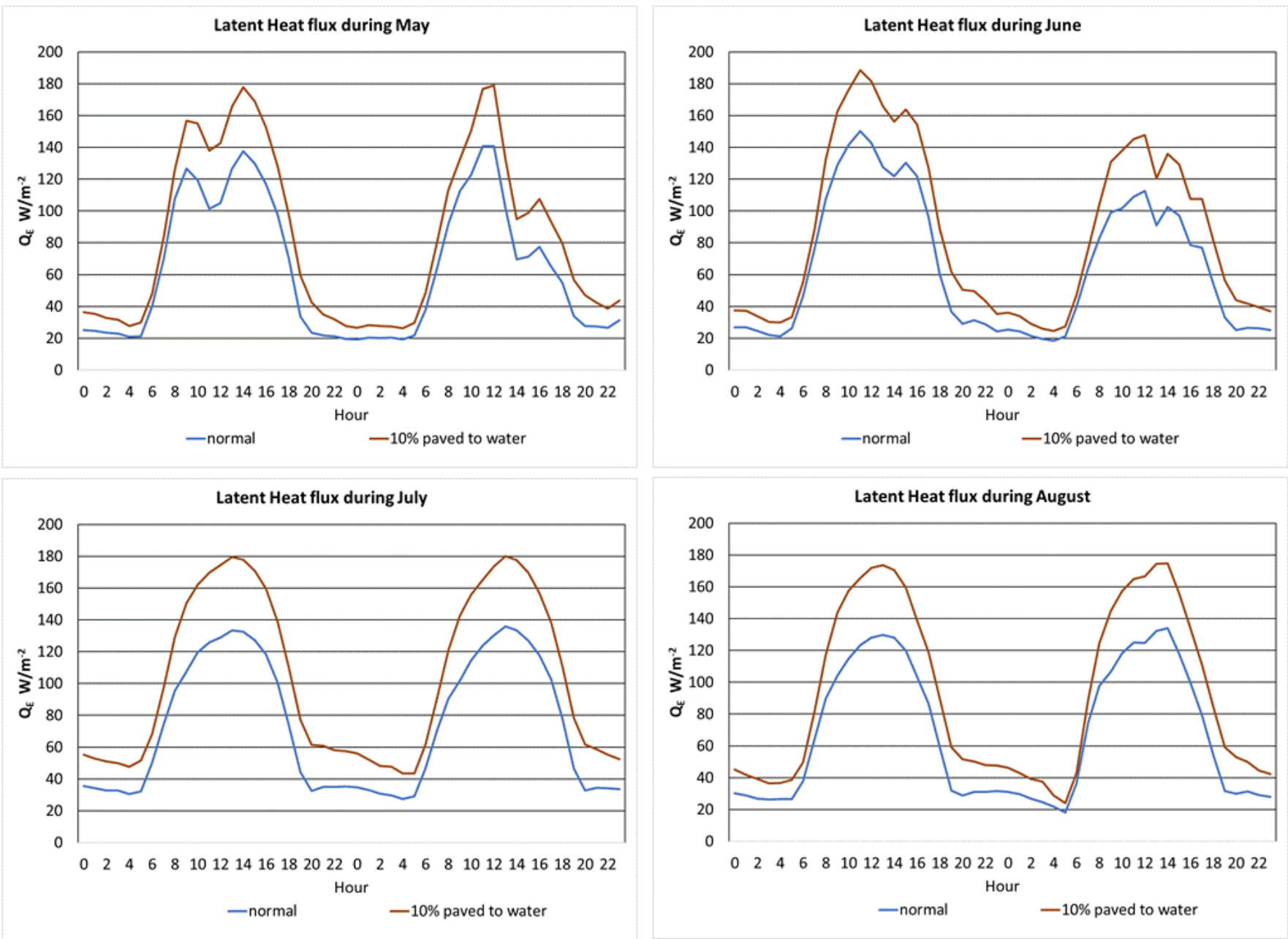

Figure 23 Turbulent Latent heat flux for 2 days during May, June, July and August for the replacement of pavements with water.

On the other hand, precipitation, irrigation, and water availability should be a significant concern in applying water bodies in cities. Using grass to replace pavements shows a reduction in the air temperature that reaches $2.27 \%$, but also using grass can achieve a decrease of $1.82 \%$. This reduction could be due to changes in the albedo that help reduce the energy balance. The rise of the turbulent latent heat flux that reaches almost $200 \%$ and the sensible heat flux reduction that reaches $100 \%$ shows that the amount of sensible heat fluxes is replaced by turbulent latent heat fluxes. This is also shown in the figures of sensible and turbulent latent heat flux (Figures 13,14,16,17,19,20). The turbulent latent heat flux from $120 \mathrm{~W} / \mathrm{m}^{2}$ in the baseline reaches $500 \mathrm{~W} / \mathrm{m}^{2}$ in some scenarios, and the sensible heat flux reduces to $100 \mathrm{~W} / \mathrm{m}^{2}$. The highest rise in turbulent latent heat flux is during August for combined roof and pavements to grass and trees that exceed $200 \%$, and this is probably due to the significant change in the surface cover, i.e., the percentage of buildings and pavements is reduced from $95 \%$ to $55 \%$. Using trees, there is a reduction about $0.79 \%$ to the temperature but not as high as when grass is used. This is probably due to the lower rise on 
albedo when the trees are applied, so the net radiation is higher than applying grass. The evapotranspiration increases more using grass. As a result, the sensible heat flux is also (Figure 10) higher $\left(100 \mathrm{~W} / \mathrm{m}^{2}\right.$ ) during the day instead of applying grass that, in every case, is lower than $100 \mathrm{~W} / \mathrm{m}^{2}$ (Figures 13,16,19).

\section{Conclusions}

The urban climate model SUEWS is evaluated and used for NBS cases to modulate the microclimate inside the local urban environment. The site of interest is a dense metropolitan area in Heraklion, Greece, and consists of buildings and pavements mostly $(\approx 93 \%)$. The model simulates the energy balance using meteorological data and incoming short-wave radiation.

The overall approach and modeling procedure has been performed according to the literature to allow comparisons with other studies. The model has a user-friendly interface, while primary remote sensing and meteorological data can provide valuable results concerning the urban fluxes. Modifying the remote sensing data, as landcover and DEMs, can offer any scenario for different site structures for several study purposes.

The use of the simple SUEWS model version used in the present study has a limitation concerning the parameterization for the characteristics of the surface components. The advanced version requires more data related to the characteristics of elements for each sub-model, anthropogenic parameters and water use of the modeled site that increase the parametrization complexity.

The study shows that incorporating green infrastructure in various forms in a densely built city reduces the air temperature above ground while decreasing the sensible heat flux considerably. The air temperature and sensible heat flux are decreased according to the increase of the various spaces' green coverage. A significant finding is the change of relative humidity and turbulent latent heat flux, which seems very high in some cases especially when the grass is incorporated. This may significantly impact the urban comfort levels and be correlated with the local climatic conditions.

Although challenging to incorporate in urban outdoor spaces, water bodies have a considerable impact on the urban environment regarding outdoor temperature reduction and relative humidity. At the same time, they create pleasant spaces for citizens.

Therefore, the incorporation of NBS in cities change the energy balances significantly and modify the urban environment for the citizens' benefit. The quantification of the NBS impact on citizens' comfort and health is of great importance. At the same time, it contributes to reducing the energy demand for cooling and mitigation of the urban heat island. 


\section{Funding}

The research is not funded by any institution

\section{Competing Interests}

The authors have declared that no competing interests exist

\section{Author Contributions}

EP: simulations, data analysis, results presentations.DK: data analysis, supervision, discussion and conclusions. NC: data quality, discussion, conclusions.

\section{Acknowledgements}

The authors would like to thank Dr Stavros Stagakis for his useful comments regarding the data processing of the EC tower and validation procedures.

\section{List of Symbols and Abbreviations}

\begin{tabular}{|l|l|l|}
\hline$Q^{*}$ & Net all-wave radiation & $\mathrm{W} / \mathrm{m}^{2}$ \\
\hline QF & Anthropogenic heat flux & $\mathrm{W} / \mathrm{m}^{2}$ \\
\hline QH & Turbulent Sensible heat flux & $\mathrm{W} / \mathrm{m}^{2}$ \\
\hline QE & Turbulent Latent heat flux & $\mathrm{W} / \mathrm{m}^{2}$ \\
\hline$\Delta Q s$ & Net storage heat flux & $\mathrm{W} / \mathrm{m}^{2}$ \\
\hline $\mathrm{P}$ & Precipitation & $\mathrm{mm}$ \\
\hline Ie & $\begin{array}{l}\text { Water supplied by irrigation or street } \\
\text { cleaning }\end{array}$ & \\
\hline $\mathrm{E}$ & Evaporation & \\
\hline $\mathrm{R}$ & Runoff & \\
\hline$\Delta S$ & Net change in the water storage & \\
\hline $\mathrm{K} \downarrow$ & Short-wave incoming radiation & $\mathrm{W} / \mathrm{m}^{2}$ \\
\hline $\mathrm{K} \uparrow$ & Short-wave outgoing radiation & $\mathrm{W} / \mathrm{m}^{2}$ \\
\hline $\mathrm{L} \downarrow$ & Longwave incoming radiation & $\mathrm{W} / \mathrm{m}^{2}$ \\
\hline L $\uparrow$ & Longwave outgoing radiation & $\mathrm{W} / \mathrm{m}^{2}$ \\
\hline FCLD & Cloud fraction & \\
\hline$\varepsilon 0$ & Emissivity of surface & \\
\hline$\varepsilon c l e a r$ & Clear-sky emissivity & \\
\hline$\sigma$ & Constant of Stefan-Boltzmann & \\
\hline T0 & Surface temperature & $\mathrm{Co}$ \\
\hline$\rho p o p$ & Population density & $\mathrm{Ha}^{-1}$ \\
\hline$\alpha F 0,1,2$ & Anthropogenic heat flux coefficients & \\
\hline a1,2,3 & OHM coefficients & \\
\hline
\end{tabular}




\begin{tabular}{|l|l|l|}
\hline$f$ & Surface cover fraction & \\
\hline$\rho$ & Density of air & $\mathrm{kg} \mathrm{m}^{-3}$ \\
\hline $\mathrm{c} \rho$ & $\begin{array}{l}\text { Specific heat capacity of air at constant } \\
\text { pressure }\end{array}$ & $\mathrm{J} \mathrm{kg}^{-1} \mathrm{~K}^{-1}$ \\
\hline rav & Vapor pressure deficit & $\mathrm{Pa}$ \\
\hline rs & aerodynamic resistance & $\mathrm{m} \mathrm{s}^{-1}$ \\
\hline rav & $\begin{array}{l}\text { Rarface resistance } \\
\text { turbulence between the surface and } \\
\text { atmosphere }\end{array}$ & $\mathrm{m} \mathrm{s}^{-1}$ \\
\hline $\mathrm{gs}$ & Surface conductance & $\mathrm{m} \mathrm{s}^{-1}$ \\
\hline $\mathrm{S}$ & $\begin{array}{l}\text { slope of the saturation vapour pressure } \\
\text { curve }\end{array}$ & $\mathrm{Pa} \mathrm{K}^{-1}$ \\
\hline$\gamma$ & Psychrometric constant & $\mathrm{Pa} \mathrm{K}$ \\
\hline LAI & Leaf area index & \\
\hline $\mathrm{g}$ & Control exerted function & \\
\hline $\mathrm{G} 1$ & Constant for gs & \\
\hline Tair & Air temperature & \\
\hline $\mathrm{p}$ & pressure & \\
\hline $\mathrm{RH}$ & Relative humidity & \\
\hline $\mathrm{U}$ & Wind speed & \\
\hline $\mathrm{z} 0$ & Roughness length & \\
\hline$\Delta \theta$ & Soil moisture deficit & \\
\hline$\Delta \mathrm{q}$ & Specific humidity deficit & \\
\hline $\mathrm{zh}$ & Displacement height & \\
\hline & & \\
\hline
\end{tabular}

\section{References}

1. UN Department of Economics and Social Affairs. World Population Prospects - Population Division - United Nations. Int J Logist Manag. 2015.

2. Caprotti F, Cowley R, Datta A, Broto VC, Gao E, Georgeson L, et al. The New Urban Agenda: key opportunities and challenges for policy and practice. Urban Res Pract. 2017;10:367-378. DOI

3. Ward HC, Kotthaus S, Järvi L, Grimmond CSB. Surface Urban Energy and Water Balance Scheme (SUEWS): Development and evaluation at two UK sites. Urban Clim. 2016;18;1-32. DOI

4. Wilby RL. Constructing climate change scenarios of urban heat island intensity and air quality. Environ Plann B Plann Des. 2008;35(5):902-919. DOI

5. Järvi L, Grimmond CSB, Christen A. The Surface Urban Energy and Water Balance Scheme (SUEWS): Evaluation in Los Angeles and Vancouver. J Hydrol. 2011;411(3-4), 219-237. DOI

6. Understanding Urban Metabolism: A Tool for Urban Planning. Chrysoulakis N, Castro E, Moors E, Ed. New York, USA: Routledge. 2015. DOI 
7. Rafael S, Martins H, Sá E, Carvalho D, Borrego C, Lopes M. Influence of urban resilience measures in the magnitude and behaviour of energy fluxes in the city of Porto (Portugal) under a climate change scenario. Sci Total Environ. 2016;566-567:1500-1510. DOI

8. Rafael S, Martins H, Marta-Almeida M, Sá E, Coelho S, Rocha A, et al. Quantification and mapping of urban fluxes under climate change: Application of WRF-SUEWS model to Greater Porto area (Portugal). Environ Res. 2017;155(October 2016):321-334. DOI

9. Vargo J, Habeeb D, Stone, B. The importance of land cover change across urban-rural typologies for climate modeling. J Environ Manage. 2013;114:243-252. DOI

10. Bonan GB. Ecological Climatology: Concepts and Applications. Cambridge,UK: Cambridge University Press. 2002.

11. Martine G, Marshall A. State of world population 2007: Unleashing the potential of urban growth. In Stateof World Population: Unleashing the Potential of Urban Growth. New York, USA: UNFPA. 2007.

12. Li D, Bou-Zeid E, Oppenheimer M. The effectiveness of cool and green roofs as urban heat island mitigation strategies. Environ Res Lett. 2014;9(5):055002. DOI

13. Kyriakodis GE, Santamouris M. Using reflective pavements to mitigate urban heat island in warm climates - Results from a large scale urban mitigation project. Urban Clim. 2017;24:326-339. DOI

14. Huynh Q, Craig W, Janssen I, Pickett W. Exposure to public natural space as a protective factor for emotional well-being among young people in Canada. BMC Public Health. 2013;13;407. DOI

15. Kolokotsa D, Lilli AA, Lilli, MA, Nikolaidis NP. On the impact of nature-based solutions on citizens' health \&amp; well being. Energy Build. 2020;229:110527. DOI

16. Raymond CM, Frantzeskaki N, Kabisch N, Berry P, Breil M, Nita MR, et al. A framework for assessing and implementing the co-benefits of nature-based solutions in urban areas. Environ Sci Policy. 2017;77(July),15-24. DOI

17. European Commission. Report from the Commission to the European Parliament and the Council - on the implementation of the EU Strategy on adaptation to climate change. 2018. COM(2018) 738 final.

18. Somarakis G, Stagakis S, Chrysoulakis N. Thinknature Nature-Based Solutions Handbook. ThinkNature project funded by the EU Horizon 2020 research and innovation programme. 2019. 730338.

19. Akbari H, Cartalis C, Kolokotsa D, Muscio A, Pisello AL, Rossi F, et al Local climate change and urban heat island mitigation techniques The state of the art. J Civ Eng Manag. 2016;22(1):1-16. DOI

20. Kolokotsa DD, Giannariakis G, Gobakis K, Giannarakis G, Synnefa A, Santamouris M. Cool roofs and cool pavements application in Acharnes, Greece. Sustain Cities Soc. 2018;37:466-474. DOI 
21. Augusto B, Roebeling P, Rafael S, Ferreira J, Ascenso A, Bodilis C. Short and medium- to long-term impacts of nature-based solutions on urban heat. Sustain Cities Soc. 2020;57:102122. DOI

22. Rafael S, Rodrigues V, Fernandes AP, Augusto B, Borrego C, Lopes M. Evaluation of urban surface parameterizations in WRF model using energy fluxes measurements in Portugal. Urban Clim. 2019;28:100465. DOI

23. Kokkonen TV, Grimmond CSB, Räty O, Ward HC, Christen A, Oke TR, et al. Sensitivity of Surface Urban Energy and Water Balance Scheme (SUEWS) to downscaling of reanalysis forcing data. Urban Clim. 2018;23:36-52. DOI

24. Järvi L, Grimmond CSB, Taka M, Nordbo A, Setälä H, Strachan IB. Development of the Surface Urban Energy and Water Balance Scheme (SUEWS) for cold climate cities. Geosci Model Dev. 2014;7(4):1691-1711. DOI

25. Alexander PJ, Fealy R, Mills GM. Simulating the impact of urban development pathways on the local climate: A scenario-based analysis in the greater Dublin region, Ireland. Landsc Urban Plan. 2016;152:72-89. DOI

26. Alexander PJ, Fealy R, Mills G. Spatial validation of an urban energy balance model using multi-temporal remotely sensed surface temperature. 2015 Joint Urban Remote Sensing Event (JURSE). 2015. $\underline{\mathrm{DOI}}$

27. Ao X, Grimmond CSB, Ward HC, Gabey AM, Tan J, Yang XQ, et al. Evaluation of the Surface Urban Energy and Water Balance Scheme (SUEWS) at a dense urban site in Shanghai: Sensitivity to anthropogenic heat and irrigation. J Hydrometeorol. 2018;19(12):1983-2005. DOI

28. Manoli G, Fatichi S, Schläpfer M, Yu K, Crowther TW, Meili N, et al. Magnitude of urban heat islands largely explained by climate and population. Nature. 2019;573(7772);55-60. DOI

29. Gobakis K, Kolokotsa D, Maravelaki-Kalaitzaki N, Perdikatsis V, Santamouris M. Development and analysis of advanced inorganic coatings for buildings and urban structures. Energy Build. 2015;89:196-205. DOI

30. Kolokotsa D, Diakaki C, Papantoniou S, Vlissidis A. Numerical and experimental analysis of cool roofs application on a laboratory building in Iraklion, Crete, Greece. Energy Build. 2012:55:85-93. DOI

31. Skoulika F, Santamouris M, Kolokotsa D, Boemi N. On the thermal characteristics and the mitigation potential of a medium size urban park in Athens, Greece. Landsc Urban Plan. 2014:123, 73-86. DOI

32. Makido Y, Hellman D, Shandas V. Nature-based designs to mitigate urban heat: The efficacy of green infrastructure treatments in Portland, Oregon. Atmosphere. 2019;10(5):282. DOI

33. Vaz Monteiro M, Doick KJ, Handley $P$, Peace A. The impact of greenspace size on the extent of local nocturnal air temperature cooling in London. Urban For Urban Green. 2016;16:160-169. DOI 
34. Lin Y, Wang Z, Jim CY, Li J, Deng J, Liu J. Water as an urban heat sink: Blue infrastructure alleviates urban heat island effect in mega-city agglomeration. J Clean Prod. 2020;262:121411. DOI

35. Xie Q, Li J. Detecting the cool island effect of urban parks in Wuhan: A city on rivers. Int J Environ Res Public Health. 2021;18(1):132. DOI

36. Järvi L, Grimmond CSB, Taka M, Nordbo A, Setälä H, Strachan, IB. Development of the Surface Urban Energy and Water Balance Scheme (SUEWS) for cold climate cities. Geosci Model Dev. 2014;7(4):1691-1711. DOI

37. Borrego C, Monteiro A, Martins H, Ferreira J, Fernandes AP, Rafael, $S$, et al. Air quality plan for ozone: an urgent need for North Portugal. Air Qual Atmos Health. 2016;9(5):447-460. DOI

38. Monteiro A, Ferreira J, Ribeiro I, Fernandes AP, Martins H, Gama C, Miranda AI. Air quality over portugal in 2020. Atmos Pollut Res. 2015;6(5):788-796. DOI

39. Rafael S, Martins H, Sá E, Carvalho D, Borrego C, Lopes M. Influence of urban resilience measures in the magnitude and behaviour of energy fluxes in the city of Porto (Portugal) under a climate change scenario. Sci Total Environ. 2016;566-567:1500-1510. DOI

40. Oke, TR. Boundary layer climates, 2nd edition. Oxfordshire, UK: Routledge. 1987.

41. Grimmond CSB, Oke TR, Steyn DG. Urban Water Balance: 1. A Model for Daily Totals. Water Resour Res. 1986;22(10):1397-1403. DOI

42. Grimmond CSB, Oke TR. An evapotranspiration-interception model for urban areas. Water Resour Res. 1991;27(7):1739-1755. DOI

43. Grimmond CSB, Cleugh HA, Oke TR. An objective urban heat storage model and its comparison with other schemes. Atmos Environ B Urban Atmos. 1991:25(3),311-326. DOI

44. Offerle B, Grimmond CSB, Oke TR. Parameterization of net all-wave radiation for urban areas. J Appl Meteorol. 2003;42(8):1157-1173. DOI

45. Grimmond CSB, Oke TR. Turbulent heat fluxes in urban areas: Observations and a local-scale urban meteorological parameterization scheme (LUMPS). J Appl Meteorol. 2002;41(7):792-810. DOI

46. Lindberg F, Grimmond S, Onomura S, Järvi LJ. Urban Multi-scale Environmental Predictor - An integrated tool for urban climatology and climate sensitive planning applications. In ICUC9 - 9th International Conference on Urban Climate jointly with 12th Symposium on the Urban Environment; July 20-24, 2015; Toulouse, France.

47. Karsisto P, Fortelius C, Demuzere M, Grimmond, CSB, Oleson KW, Kouznetsov R, et al. Seasonal surface urban energy balance and wintertime stability simulated using three land-surface models in the high-latitude city Helsinki. Q J R Meteorol. 2016;142(694):401417. DOI 
48. Alexander PJ, Mills G, Fealy R. Using LCZ data to run an urban energy balance model. Urban Clim. 2015;13:14-37. DOI

49. Loridan T, Grimmond CSB. Characterization of energy flux partitioning in urban environments: Links with surface seasonal properties. J Appl Meteorol Climatol. 2012;51(2):219-241. DOI

50. Crawford TM, Duchon CE. An improved parameterization for estimating effective atmospheric emissivity for use in calculating daytime downwelling longwave radiation. J Appl Meteorol. 1999;38(4):474-480. DOI

51. Chrysoulakis N, Grimmond CSB. Understanding and reducing the anthropogenic heat emission. In Urban Climate Mitigation Techniques. Oxfordshire, UK:Routledge 2016:27-40. DOI

52. Sailor DJ, Georgescu M, Milne JM, Hart MA. Development of a national anthropogenic heating database with an extrapolation for international cities. Atmos Environ. 2015;118:7-18. DOI

53. Kłysik K. Spatial and seasonal distribution of anthropogenic heat emissions in Lodz, Poland. Atmos Environ. 1996;30(20):3397-3404. DOI

54. Taha H. Urban climates and heat islands: Albedo, evapotranspiration, and anthropogenic heat. Energy Build. 1997;25(2):99-103. DOI

55. Hamilton IG, Davies M, Steadman P, Stone A, Ridley I, Evans S. The significance of the anthropogenic heat emissions of London's buildings: A comparison against captured shortwave solar radiation. Build Environ. 2009;44(4):807-817. DOI

56. Ichinose $T$, Shimodozono K, Hanaki K. Impact of anthropogenic heat on urban climate in Tokyo. Atmos Environ. 1999;33(24-25):38973909. DOI

57. Sailor DJ, Vasireddy C. Correcting aggregate energy consumption data to account for variability in local weather. Environ Model Softw. 2006;21(5):733-738. DOI

58. Ward HC, Evans JG, Grimmond CSB. Multi-season eddy covariance observations of energy, water and carbon fluxes over a suburban area in Swindon, UK. Atmospheric Chem Phys. 2013;13(9):46454666. DOI

59. Doll D, Ching JKS, Kaneshiro J. Parameterization of subsurface heating for soil and concrete using net radiation data. Bound-Layer Meteorol. 1985;32(4):351-372. DOI

60. McCaughey $\mathrm{JH}$. Energy balance storage terms in a mature mixed forest at Petawawa, Ontario - A case study. Bound-Layer Meteorol. 1985;31(1):89-101. DOI

61. Yoshida A, Tominaga K, Watatani S. Field measurements on energy balance of an urban canyon in the summer season. Energy Build. 1990;15(3-4):417-423. DOI

62. Arnfield AJ, Grimmond CSB. An urban canyon energy budget model and its application to urban storage heat flux modeling. Energy Build. 1998;27(1):61-68. DOI 
63. Meyn SK, Oke TR. Heat fluxes through roofs and their relevance to estimates of urban heat storage. Energy Build. 2009;41(7): 745-752. DOI

64. Sun $\mathrm{T}$, Wang $\mathrm{ZH}, \mathrm{Ni} \mathrm{GH}$. Revisiting the hysteresis effect in surface energy budgets. Geophys Res Lett. 2013;40(9):1741-1747. DOI

65. Grimmond CSB, Oke TR. Heat storage in urban areas: Local-scale observations and evaluation of a simple model. J Appl Meteorol. 1999;38(7):922-940. DOI

66. Roberts SM, Oke TR, Grimmond CSB, Voogt JA. Comparison of four methods to estimate urban heat storage. J Appl Meteorol Climatol. 2006;45(12):1766-1781. DOI

67. Stewart JB. Modelling surface conductance of pine forest. Agric For Meteorol. 1988;43(1):19-35. DOI

68. Ogink-Hendriks MJ. Modelling surface conductance and transpiration of an oak forest in The Netherlands. Agric For Meteorol. 1995;74(1-2):99-118. DOI

69. Krinner G, Viovy N, de Noblet-Ducoudré N, Ogée J, Polcher J, Friedlingstein $\mathrm{P}$, et al. A dynamic global vegetation model for studies of the coupled atmosphere-biosphere system. Global Biogeochem Cycles 2005;19(1). DOI

70. Best MJ, Pryor M, Clark DB, Rooney GG, Essery RLH, Ménard CB, et al. The Joint UK Land Environment Simulator (JULES), model description - Part 1: Energy and water fluxes. Geosci Model Dev. 2011;4(3):677-699. DOI

71. De Kauwe MG, Kala J, Lin YS, Pitman AJ, Medlyn BE, Duursma RA, et al. A test of an optimal stomatal conductance scheme within the CABLE land surface model. Geosci Model Dev. 2015;8(2):431-452. DOI

72. Jarvis PG. The interpretation of the variations in leaf water potential and stomatal conductance found in canopies in the field. Philos Trans R Soc Lond B Biol Sci. 1976;273(927);593-610. DOI

73. Chrysoulakis N, Grimmond S, Feigenwinter C, Lindber, F, GastelluEtchegorry JP, Marconcini $M$, et al. Urban energy exchanges monitoring from space. Sci Rep. 2018. DOI

74. Christen A, Grimmond CSB, Roth M, Pardyjak E. The IAUC Urban Flux Network An international network of micrometeorological flux towers. (December). Eos Trans AGU. 2009;90(52).

75. Arnfield J. Köppen climate classification. Encyclopedia Britannica. 2017.

76. Stagakis S, Chrysoulakis N, Spyridakis N, Feigenwinter C, Vogt R. Eddy Covariance measurements and source partitioning of $\mathrm{CO} 2$ emissions in an urban environment: Application for Heraklion, Greece. Atmospheric Environment. 2019;201,278-292. DOI

77. Marconcini M, Heldens W, Del Frate F, Latini D, Mitraka Z, Lindberg F. EO-based products in support of urban heat fluxes estimation. 2017 Joint Urban Remote Sensing Event (JURSE). 2017. DOI 
78. Lindberg F, Grimmond CSB, Gabey A, Huang B, Kent CW, Sun T, et al. Urban Multi-scale Environmental Predictor (UMEP): An integrated tool for city-based climate services. Environ Model Softw. 2018;99:70-87. DOI

79. Sun T, Järvi L, Omidvar H, Theeuwes N, Lindberg F, Li Z, Grimmond S. Urban-Meteorology-Reading/SUEWS: 2019a Release. 2019. DOI

80. Stagakis S, Burud I, Thiis T, Gaitani N, Panagiotakis E, Lantzanakis G, et al. Spatiotemporal monitoring of surface temperature in an urban area using UAV imaging and tower-mounted radiometer measurements. 2019 Joint Urban Remote Sensing Event (JURSE). 2019. DOI

81. Kotthaus S, Grimmond CSB. Energy exchange in a dense urban environment - Part II: Impact of spatial heterogeneity of the surface. Urban Clim. 2014;10:281-307. DOI

Cite this article: Panagiotakis E, Kolokotsa D, Chrysoulakis N. Evaluation of nature-based solutions implementation scenarios, using urban surface modelling. Green Energy Sustain 2021;1(1):0003. https://doi.org/10.47248/HKOD902101010003 